\title{
Immuno-moodulin: a new anxiogenic factor produced by Annexin- A1 transgenic autoimmune-prone T cells
}

Giuseppa Piras ${ }^{1,} \uparrow$, Lorenza Rattazzi ${ }^{1}$, Nikolaos Paschalidis ${ }^{1}$, $\dagger$, Silvia Oggero ${ }^{1}$, Giulio Berti ${ }^{1}$, Masahiro Ono ${ }^{2}$, Fabio Bellia ${ }^{3}$, Claudio D'Addario ${ }^{3}$, Bernardo Dell'Osso ${ }^{4}$, Carmine Maria Pariante ${ }^{5}$, Mauro Perretti 1,6, Fulvio D’Acquisto 1,6,7*§

${ }^{1}$ William Harvey Research Institute, Barts and the London School of Medicine and Dentistry, Queen Mary University of London, London, United Kingdom;

${ }^{2}$ Department of Life Sciences, Faculty of Natural Sciences, Imperial College London, London,United Kingdom;

${ }^{3}$ Faculty of Bioscience, University of Teramo, Teramo, Italy; Department of Clinical Neuroscience, Karolinska Institutet, Stockholm, Sweden.

${ }^{4}$ University of Milan, Department of Biomedical and Clinical Sciences "Luigi Sacco", ASST Fatebenefratelli Sacco, Ospedale Sacco, Polo Universitario, Milan, Italy; CRC "Aldo Ravelli" for Neurotechnology and Experimental Brain Therapeutics, University of Milan, Italy; Department of Psychiatry and Behavioral Sciences, Bipolar Disorders Clinic, Stanford University, CA, USA.

${ }^{5}$ Institute of Psychiatry, Psychology and Neuroscience, King's College, London, United Kingdom;

${ }^{6}$ Centre for inflammation and Therapeutic Innovation, Queen Mary University of London, London, United Kingdom;

${ }^{7}$ Health Science Research Centre, Department of Life Science, University of Roehampton, London, United Kingdom.

*Correspondence to: Fulvio D’Acquisto, Centre for Biochemical Pharmacology, The William Harvey Research Institute, Barts and the London School of Medicine, Charterhouse Square, London, EC1M 6BQ, United Kingdom. Tel: 44207882 6081. Fax: 44207882 6076. E-mail: F.Dacquisto@qmul.ac.uk.

$\S$ Present address: Health Science Research Centre, Department of Life Science, University of Roehampton, London, SW15 4JD, UK. Tel: 44207882 6081. Fax: 44207 882 6076. E-mail: Fulvio.DAcquisto@roehampton.ac.uk

$\uparrow$ Molecular and Cellular Immunology department, Great Ormond Street Institute of Child Health, UCL, 30 Guilford Street, London WC1N 1EH

† Cellular Immunology Laboratory, Center for Basic Research, Biomedical Research Foundation of the Academy of Athens, 11527 Athens, Greece 
Piras et al

Page $\mathbf{2}$ of $\mathbf{3 1}$ 


\section{Abstract}

Patients suffering from autoimmune diseases are more susceptible to mental disorders yet, the existence of specific cellular and molecular mechanisms behind the co-morbidity of these pathologies is far from being fully elucidated. By generating transgenic mice overexpressing Annexin-A1 exclusively in $\mathrm{T}$ cells to study its impact in models of autoimmune diseases, we made the unpredicted observation of an increased level of anxiety. Gene microarray of Annexin-A1 $\mathrm{CD}^{+} \mathrm{T}$ cells identified a novel anxiogenic factor, a small protein of approximately $21 \mathrm{kDa}$ encoded by the gene 2610019F03Rik which we named Immuno-moodulin. Neutralizing antibodies against Immuno-moodulin reverted the behavioral phenotype of Annexin-A1 transgenic mice and lowered the basal levels of anxiety in wild type mice; moreover, we also found that patients suffering from obsessive compulsive disorders show high levels of Imood in their peripheral mononuclear cells. We thus identify this protein as a novel peripheral determinant that modulates anxiety behavior. Therapies targeting Immuno-moodulin may lead to a new type of treatment for mental disorders through regulation of the functions of the immune system, rather than directly acting on the nervous system. 
The challenging life of patients diagnosed with autoimmune diseases is often further impoverished by the emergence of mental disorders as a major co-morbidity (Coutinho and Vincent, 2016; Khandaker et al., 2017). For instance, if we only consider multiple sclerosis, $\sim 40 \%$ of patients suffering from this disease have attempted suicide (Feinstein and Pavisian, 2017; Pompili et al., 2012). The incidence of as major depression are significantly higher and is correlated with the progression of the disease (Lorefice et al., 2015). Finally, a large study conducted on more than 4000 subjects enrolled on the UK Multiple Sclerosis Register showed that anxiety and depression were notably high, with $54.1 \%$ of patients scoring $>8$ for anxiety and $46.9 \%$ scoring $>8$ for depression on the Hospital Anxiety and Depression Scale (HADS)(Jones et al., 2012).

Similar observations have been made for other autoimmune conditions. More than $30 \%$ of patients affected by autoimmune hepatitis suffer from schizophrenia (Butt et al., 2006; Cournos et al., 2005). Meta-analysis studies on the prevalence of depression and anxiety in rheumatoid arthritis (Matcham et al., 2013) or systemic lupus erythematosus (Moustafa et al., 2020) patients have revealed a high variability in the prevalence of anxiety or major depression but in any case ranges of incidence from about 10 to $80 \%$ depending on the scale that was used. Most strikingly, immunomodulatory therapies for the treatment of autoimmune conditions might aggravate the emergence of these problems (Bosche et al., 2015) thus presenting both clinicians and patients with a paradoxical dilemma: the physical symptoms of autoimmunity might be effectively improved at the expenses of a worsening of the emotional state and wellbeing. This is for instance the case of interferon beta (IFN- $\beta$ ) that is currently used as an effective treatment for multiple sclerosis but its use is limited by the increased incidence of suicidal thoughts in a significant proportion of patients (Goeb et al., 2006). Although some studies have investigated the functional crosstalk between the brain and the immune system (Dantzer, 2018; Marin and Kipnis, 2017) it is still not clear how one system influences the other and if there is a common root or determinant for the emergence of mental disorders in autoimmune conditions.

Annexin-A1 (AnxA1) is an endogenous modulator of a variety of physiological and pathological processes ranging from inflammation (Leoni and Nusrat, 2016; Perretti and D'Acquisto, 2009) and cancer (Boudhraa et al., 2016; Guo et al., 2013; Moraes et al., 2018). As with many other multifunctional mediators, AnxA1 plays a homeostatic role in the immune system as it can exert both positive and negative functions depending on the contexts. In the context of $\mathrm{T}$ cells, studies have indeed provided contrasting and opposite results showing that it can act as both a positive (D'Acquisto et al., 2007a; D'Acquisto et al., 2007b; D'Acquisto et al., 2013; Huang et al., 2016; Huggins et al., 2009; Mihaylova et al., 2017; Paschalidis et al., 2010; Paschalidis et al., 2009; Sena et al., 2016; Tzelepis et al., 2015) and a negative modulator of T cell activation (Odobasic et al., 2018; Sena et al., 2016; Yang et al., 2013; Yazid et al., 2015). All these studies have been done using either exogenously administered recombinant AnxA1 (and its mimetic) or AnxA1-deficient mice where the protein is absent in every immune cell. Aiming to address these controversies, we have generated a $T$ cell specific AnxA1 transgenic mouse colony (AnxA1 ${ }^{\text {tg }}$ ) to address the biology of this mediator.

In this paper, analysis of AnxA1 ${ }^{\text {tg }}$ response in experimental model of autoimmunity showed exacerbated signs of inflammation. However, besides their autoimmune-prone 
phenotype, AnxA1 ${ }^{\text {tg }}$ mice displayed an unexpected high level of compulsive digging that was noticeable even in their home cage and at basal physiological settings e.g. in mice that were not subjected to any inflammatory condition. Further exploration on the molecular mechanisms behind this phenotype of anxiety led us to the discovery of a new homeostatic modulator that we named Immuno-moodulin (Imood) - because of its discovery in T cells. Immuno-moodulin levels in mice affect their intrinsic basal level of anxiety. In addition, we found that patients suffering from OCD present high levels of Imood in their peripheral blood mononuclear cells. The results of this study expand our knowledge of the complex interactions and intersection between the immune and the central nervous system.

\section{Materials and Methods}

\section{Reagents}

Unless otherwise stated, all the chemicals were purchased from Sigma. For the convenience of the readers all the antibodies used in the study have been reported in Table 4 as well as in the figure legends.

\section{Animals and husbandry}

Wild type C57BL/6J (B6-CD45.2) and B6.SJL-Ptprca Pepcb/BoyJ (B6-CD45.1) were purchased from Charles River. AnxA1 ${ }^{\text {tg }}$ mice were generated in the in-house transgenic mouse facility of Queen Mary University of London by pronuclear injection.

Mice were housed in groups of 6 per cage under specific-pathogen-free conditions and with free access to food and water. Mice were housed for at least 7 days prior to testing. All experiments were performed during the light phase of the light-dark cycle and no more than 2 tests per day were performed. The results presented in this manuscript were obtained using male mice (6-8 weeks old) because - unlike in humans - both the intensity and incidence of inflammatory/autoimmune disease are more pronounced in male mice. However, the difference we observed in terms of both immune response and behavioral changes were confirmed and reproducible in female mice (data not shown). All tests were conducted under license from the Home Office and according to the UK Animals (Scientific Procedures) Act, 1986. All experiments were approved and performed under the guidelines of the Ethical Committee for the Use of Animals, Bart's and The London School of Medicine and Home Office Regulations (57) (PPL 80/8714).

To monitory the transgenic colony, genomic DNA were extracted from ear clips by using REDExtract N-AMP -XNAT kit (Sigma, UK) and analysed by PCR with the following specific primers for AnxA $1^{\text {tg }}$ : forward primer 5' G TAT GG A ATC TC TCT T TGCCAAGC-3' ; reverse primer is 5' ACHGATATGCACATCAGGAGGG-3' (Thermo Scientific, UK). The parameters of the PCR reactions are: initial denaturation at $94^{\circ} \mathrm{C}$ for $3 \mathrm{~min}$ followed by 30 cycles of denaturation at $94^{\circ} \mathrm{C}$ for $45 \mathrm{sec}$, annealing at $60^{\circ} \mathrm{C}$ for $45 \mathrm{sec}$ and extension time at $72^{\circ} \mathrm{C}$ for $15 \mathrm{sec}$, and afterwards a final extension step at $72^{\circ} \mathrm{C}$ for $7 \mathrm{~min}$.

All the behavioral tests were video-recorded and analyzed double-blind during the light phase of the light-dark cycle, as previously described(McIlwain et al., 2001). The scoring and analysis of the data was hand-made by at least 2 blinded independent experimenters. All the efforts were made to minimize mouse discomfort in these behavioral experiments. 
Mice were brought to the testing room at least 30 minutes before the start of the test session to allow habituation to the testing environment. All behavioral equipment was thoroughly cleaned and sanitized at the end of the day and in between tests. Unless otherwise specified, standard lighting (about 50 lux) and quiet conditions were maintained throughout each experiment.

\section{Generation of $\mathbf{T}$ cell-specific $\operatorname{AnxA1}{ }^{\text {tg }}$ mice}

To generate the VACD2 AnxA1 FLAG transgenic mice, murine AnxA1 gene was extracted, amplified and tagged with the FLAG epitope. The gene was cloned in TOPO pcDNA3.1 vector for verification of its expression in vitro and finally subcloned in the VACD2 vector (Zhumabekov et al., 1995) for T cell specific expression in the mouse. Finally, the VACD2 AnxA1 FLAG construct was modified and purified for the pronuclear microinjection into the mouse genome.

\section{Flow cytometric analysis}

Single cell suspension of thymocytes or lymphocytes from spleen and lymph nodes were obtained as previously described (Paschalidis et al., 2010; Rattazzi et al., 2013). Briefly, tissues were gently desegregated in RPMI medium supplemented with $100 \mathrm{U} / \mathrm{ml}$ of penicillin and streptomycin (PAA laboratories, Buckinghamshire, UK) using a 70 $\mathrm{mm}$ mesh cell strainer (Falcon, UK) and the piston of a $5 \mathrm{ml}$ syringe. Cell suspensions from spleen and lymph nodes were layered onto Histopaque-1077 (Sigma-Aldrich, Dorset, England) in a ratio $3: 1$ and centrifuged at $400 \mathrm{~g}$ for 10 mins to isolate mononuclear cells. The resulting buffy coat was collected and washed twice with RPMI supplemented with $100 \mathrm{U} / \mathrm{ml}$ of penicillin and streptomycin (PAA laboratories, Buckinghamshire, UK) and then suspended in FACS buffer (phosphate-buffered saline containing 5\% fetal calf serum and $0.02 \%$ of $\mathrm{NaN}_{2}$ ) for further analysis. Thymocytes were washed twice with RPMI supplemented with $100 \mathrm{U} / \mathrm{ml}$ of penicillin and streptomycin (PAA laboratories, Buckinghamshire, UK) and then suspended in FACS buffer. Aliquots of cell suspensions were used to evaluate the total number of cells using a standard hematocytometer. Cells were stained in $100 \mu \mathrm{l}$ of FACS buffer containing the following fluorochrome-conjugated antibodies: anti-CD3 (clone 145-2C11), anti-CD4 (clone GK 1.5), anti-CD8 (clone 53-6.7) (all from eBioscience, San Diego, CA, USA). Cells were labeled with the appropriate concentration of conjugated antibodies for $1 \mathrm{~h}$ at $4^{\circ} \mathrm{C}$. After labeling, cells were washed and analyzed using FACScalibur flow cytometer. Results were analyzed using the FlowJoTM software (Tree Star, Ashland, OR, USA, Oregon Corporation).

\section{$T$ cell activation assay}

Lymph node T cells $\left(1 \times 10^{5}\right.$ cells/200 $\left.\mu \mathrm{l}\right)$ were incubated with medium alone or stimulated by plate-bound anti-CD3 (clone 145-2C11; eBioscience) and anti-CD28 (clone 37.51; eBioscience) for 24 hours in 96-well plates. For CD25 and CD69 upregulation, lymph node $\mathrm{T}$ cells were stimulated with plate-bound anti-CD3 and anti-CD28 as indicated in the figure. After 16 hours, the cells were stained with PE-conjugated anti-CD69 (clone $\mathrm{H} 1.2 \mathrm{~F} 3$ ) and FITC-conjugated anti-CD25 (clone PC61.5) diluted in FACS buffer (PBS containing $1 \%$ FCS and $0.02 \% \mathrm{NaN}_{2}$ ). The polyclonal antibody against Tdrp (Imood) was purchased from Novusbio (catalogue number NBP1-93675). The secondary antibody was a goat anti-rabbit Alexa Fluor 488-conjugated IgG from Abcam (catalogue number 
ab150077). Intact cells were gated by using forward and side scatter and analyzed with the FlowJoTM software (Tree Star, Ashland, OR, USA, Oregon Corporation). IL-2 production was measured after 24 or $48 \mathrm{hr}$ of stimulation using a standard ELISA kit and according to the manufacturer's instructions (eBioscience).

\section{Intracellular staining and cytometric bead assay}

Th cell phenotype was studied by intracellular staining. Lymphocytes were isolated from $\mathrm{MOG}_{35-55}$ immunized mice from peripheral lymphoid organs and spinal cord. Lymphocytes $\left(10 \times 10^{6}\right.$ cells $\left./ \mathrm{ml}\right)$ from lymph nodes and spleen were cultured for 72 hours with either medium alone (CTRL) or with anti-CD3 (clone 145-2C11; eBioscience) and anti-CD28 (clone 37.51; eBioscience) antibodies $(1 \mu \mathrm{g} / \mathrm{ml}$; plate bound) or with the specific antigen $\mathrm{MOG}_{35-55}(100 \mu \mathrm{g} / \mathrm{ml})$. At third day, the cells were pelleted and the supernatants stored at $-20^{\circ} \mathrm{C}$. Subsequently, the cells were re-challenged with concanavalin A (ConA, $5 \mu \mathrm{g} / \mathrm{ml}$; Sigma) in presence of protein transport inhibitor Brefeldin A (1:1000; eBioscience) for 4 hours. Mononuclear cells isolated from the spinal cords instead were directly triggered with ConA and Brefeldin A after collection.

Cells were pelleted and then stained for CD4 (clone GK 1.5; eBioscience) for half an hour and fixed with $1 \%$ PFA for 10 minutes. Thereafter, cells were permeabilized and stained for $30 \mathrm{~min}$ in permeabilization buffer (eBioscience) containing conjugated antibodies (all from eBioscience) for cytokines (dil: 1:250) such as IFN $\gamma$ (clone XMG1.2), IL-17 (eBioTC11-18H10.1), GM-CSF (clone MP1-22E9) and IL-10 (clone JES5-16E3). Finally, cells were washed and suspended in FACS buffer for flow cytometer analysis.

\section{Cytometric bead array}

Cytokine production was measured by bead-based analytic assay in flow cytometry. We used a custom-designed Mouse Th1/Th2/ Th17/Th22 13plex kits supplemented with

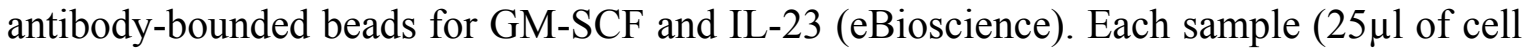
culture supernatant) was incubated with $50 \mu \mathrm{l}$ bead mixture and $50 \mu 1 \mathrm{mix}$ of antibodies conjugated with biotin for $2 \mathrm{~h}$. After two washes, streptavidin PE conjugated antibodies was added and samples were let rocking for 1 hour in dark. Finally, samples were washed and stored overnight at $4^{\circ} \mathrm{C}$. Standards diluted serially for 7 times were prepared and processed at the same time. Samples were analysed using a BD LSR Fortessa using the following voltage settings: FSC 444, SSC 250, YG-585/15 channel 430, R-670/14 channel 400.

\section{Histology}

Intact spinal cords were first fixed in 4\% paraformaldehyde for $72 \mathrm{~h}$ and then incubated with decalcifying solution containing EDTA ( $0.1 \mathrm{mM}$ in PBS) for 14 days prior to paraffin embedding. Tissues sections $(5 \mu \mathrm{m})$ were deparaffinized with xylene and stained with hematoxylin and eosin (H\&E) by our in-house histology facility (https:// www.bci.qmul.ac.uk/en/research/lab-facilities/pathology). Photos of the sections were acquired using an Olympus BX61 available at the in-house pathology facility. In all cases, a minimum of three sections per animal was evaluated. Phase-contrast digital images were taken using the Image Image-Pro (Media Cybernetics, Rockville, MD, USA) analysis software package. 


\section{MOG35-55-induced Experimental Autoimmune Encephalomyelitis}

Male C57BL/6 mice received an intradermal injection of $300 \mu \mathrm{g}$ of $\mathrm{MOG}_{35-55}$ (MEVGWYRSPFSRVVHLYRNGK, synthetized by Cambridge Research Biochemicals, UK; Cambridge Research Biochemicals) emulsified in Complete Freund's adjuvant (CFA; Sigma-Aldrich, Dorset, England) and two doses of 500ng of pertussis toxin (PTX; SigmaAldrich, Dorset, England) at day zero and day two as previously reported (Paschalidis et al., 2009). The severity of the disease was scored on a scale of 0 to 6 with $0=$ no neurological signs, $1=$ tail weakness, $2=$ tail paralysis, $3=$ loss of righting reflex (the mouse can no longer right themselves after being laid on their back), $4=$ hind leg paralysis, $5=$ quadriplegia and $6=$ death.

\section{Leukocytes isolation from central nervous system}

Vertebral columns were dissected from the lumbar to the cervical region and washed several times in PBS to remove blood trace. Spinal cords were extracted by hydro pressure in the spinal canal by using a $2 \mathrm{ml}$ syringe and 19-gauge needle. Subsequently, tissues were torn apart in sterile PBS by mechanical pressure through a $70 \mu \mathrm{m}$ mesh cell strainer (Falcon). Mononuclear cells and lymphocytes were isolated by density gradient centrifugation in Percoll (GE Healthcare). In detail, cells were pelleted at 400xg for 5 min and suspended in a 30\% Percoll solution. The $30 \%$ Percoll solution was carefully layered onto a $70 \%$ Percoll solution in a ratio $1: 2$ and centrifuged at $500 \times \mathrm{xg}$ for $30 \mathrm{~min}$. In this density gradient mononuclear cells sediment at the interface between $30 \%$ and $70 \%$ Percoll layers. About 2-3ml of interface solution was collected only after the fatty layer at the top of the centrifuge tube was carefully removed. The purified mononuclear cells were washed twice in RPMI supplemented with $100 \mathrm{U} / \mathrm{ml}$ of penicillin and streptomycin and $10 \%$ of FCS (Invitrogen).

\section{Pristane-induced lupus}

Wild type or AnxA1 ${ }^{\text {tg }}$ male mice received received a single $0.5 \mathrm{ml}$ i.p. injection of sterile pristane (Sigma-Aldrich, St Louis, MO, USA). Weight was recorded every other day or every 3 days for over 5 weeks. In some experiments, mice were culled after 4 weeks and

the spleen and lung collected for histological analysis. The weight of the spleen was also measured to compare the level of splenomegaly between wild type or AnxA1tg.

\section{Digging and marble-burying tests}

Marble-burying and digging tests were carried out as described previously (Gallo et al., 2014) with some modifications. Briefly, mice were individually placed in a clear plastic box $(48 \mathrm{~cm} \times 39 \mathrm{~cm} \times 31 \mathrm{~cm})$ filled with approximately 5 -cm-deep wood chip bedding lightly pressed to give a flat surface. The same bedding substrate was used for all the mice and flattened after each test. Twenty glass marbles were placed on the surface in five rows of 4 marbles each. The latency to start digging, the number of digging bouts and the number of buried marbles (to $2 / 3$ their depth) were recorded during the 10 min test.

\section{Climbing activity test}

The climbing test is used to assess vertical activity and exploratory behavior. The test was performed as previously described (Gallo et al., 2014). Briefly, mice were placed, one at a 
time, on a thin layer of fresh wood chip bedding on a laboratory bench and covered with a cylindrical climbing mesh (60 $\mathrm{cm}$ x $30 \mathrm{~cm}$ base diameter). They were each observed and recorded for 5 minutes. The number of climbing events and total duration of climbing activity was assessed. The criterion for climbing was for a mouse to have all 4 feet on the wire mesh while a climb terminated as soon as one foot touched the bench. This test was conducted in the late afternoon, when mice are known to be more active.

\section{Light-dark shuttle box}

In this test exploratory activity reflects the combination of hazard and risk avoidance (Bourin and Hascoet, 2003) The apparatus consisted of a $45 \mathrm{~cm}$ x $20 \mathrm{~cm}$ x $21 \mathrm{~cm}$ box, divided into two distinct compartments: one third (15 cm long) painted black, with a black lid on top, the remaining two thirds painted white and uncovered. A $2.5 \mathrm{~cm} \times 2.5 \mathrm{~cm}$ opening joined the two compartments. One side of the bright box was transparent to enable behavioral assessment and the averseness of this compartment was increased by additional illumination supplied by a $50 \mathrm{~W}$ lamp placed $45 \mathrm{~cm}$ above the centre of the box floor. The test was performed in accordance with a previous published protocol (Bourin and Hascoet, 2003). Each mouse was placed in the bright compartment, facing away from the opening and allowed to explore the box for 5 minutes. Dependent variables included the time spent in the light area, latency to cross to the dark area (all four paws in) and the total number of transitions between compartments. The apparatus was cleaned after each trial.

\section{Open field activity test}

The open filed test was performed as described previously (Gallo et al., 2014). The open field consisted of a white PVC arena $(50 \mathrm{~cm} \times 30 \mathrm{~cm})$ divided into $10 \mathrm{~cm} \times 10 \mathrm{~cm}$ squares. Mice were brought into the experimental room $15 \mathrm{~min}$ before testing. Each mouse was placed in one of the corner squares facing the wall, observed and recorded for $5 \mathrm{~min}$. The total number of squares crossed, latency to the first rear and the total number of rears were recorded. After each test, the arena was cleaned with water to attenuate and homogenize olfactory traces.

\section{Real-time polymerase chain reaction}

Total RNA was extracted from brains of wild type and AnxA1 $1^{\text {tg }}$ mice RNeasy Microarray Tissue Mini Kit (Qiagen, West Sussex, UK) while for the purified CD4 ${ }^{+} \mathrm{T}$ cells we used RNeasy Mini Kit from the same manufacturer. Meninges were removed by gently rolling the brains on Whatman paper. Total RNA was reverse transcribed using $2 \mathrm{mg}$ oligo(dT) 15 primer, $10 \mathrm{U}$ AMV reverse transcriptase, 40U RNase inhibitor (all from Promega Corporation, Madison, WI, USA) and $1.25 \mathrm{mM}$ each dNTP (Bioline, London, UK) for 45 min at $42^{\circ} \mathrm{C}$. Real-time polymerase chain reaction was carried out by using ABsoluteTM QPCR ROX Mix (Thermo Scientific, Epsom, UK) and fluorescent QuantiTect primers (Qiagen, West Sussex, UK). The human and murine primers for Tdrp were HsTDRP1SG and MmTdrp1SG. Cycling conditions were set according to the manufacturer's instructions. Sequence-specific fluorescent signal was detected by $7900 \mathrm{HT}$ Fast RealTime PCR System (Applied Biosystems, Warrington, Cheshire, UK). mRNA data were normalized relative to glyceraldehyde 3-phosphate dehydrogenase and then used to calculate expression levels. We used the comparative $\mathrm{Ct}$ method to measure the gene 
transcription in samples. The results are expressed as relative units based on calculation of $2^{-\Delta \Delta \mathrm{Ct}}$, which gives the relative amount of gene normalized to endogenous control (glyceraldehyde 3-phosphate dehydrogenase) and to the sample with the lowest expression set as 1 .

Total RNA was also isolated from PBMCs of OCD subjects and healthy controls according to the method of Chomczynski and Sacchi (Chomczynski and Sacchi, 1987) RTPCR reactions were performed using the RevertAid H Minus First Strand cDNA Synthesis Kit (Thermo Scientific, Waltham, MA, USA). The relative abundance was assessed by RTqPCR using iQ SYBR Green Supermix (Hercules, CA, USA) on a DNA Engine Opticon 2 Continuous Fluorescence Detection System (MJ Research, Waltham, MA, USA). To provide precise quantification of the initial target in each PCR reaction, the amplification plot was examined and the point of early log phase of product accumulation defined by assigning a fluorescence threshold above background, defined as the threshold cycle number or Ct. Differences in threshold cycle number were used to quantify the relative amount of the PCR targets contained within each tube. After PCR, a dissociation curve (melting curve) was constructed in the range of 60 to $95{ }^{\circ} \mathrm{C}$ to evaluate the specificity of the amplification products. The relative expression of different amplicons was calculated by the delta-delta $\mathrm{Ct}(\Delta \Delta \mathrm{Ct})$ method and converted to relative expression ratio $\left(2^{-} \Delta \mathrm{Ct}\right)$ for statistical analysis. All human data were normalized to the endogenous reference genes $\beta$ actin and GAPDH combined.

\section{Microarray analysis}

Total RNA was hybridized to Affymetrix Mouse Gene 1.0 ST array chips at UCL Genomics (London, UK) with standard Affymetrix protocols, using GeneChip Fluidics Station 450, and scanned using the Affymetrix GeneChip Scanner (Affymetrix, Santa Clara, CA, USA). Computational analysis was performed using Mac OS 10.6.8, and R version 3.1.0. affymetrix platform MoGene_1.0st transcript cluster. Heatmap was generated by the function heatmap. 2 of the CRAN package, gplots, using the completelinkage clustering using the Euclidean distance. Data was normalized by robust multiarray average (RMA) of the Bioconductor package, affy. Relevant genes were filtered by excluding those without an Entrez ID and those with low expression levels less than 100 by non-logged value. T-statistics were applied across the data set using the Bioconductor package Limma considering the false discovery rate and differentially expressed genes were identified by $\mathrm{P}<0.05$ (non-adjusted $\mathrm{P}$ value).

\section{Western blotting analysis}

Lymph node and splenic $\mathrm{T}$ cells or purified $\mathrm{CD}^{+} \mathrm{T}$ cells were stimulated as indicated in figures. To obtain the whole cell lysate, cells were resuspended in ice-cold lysis buffer (1\% NP-40, $20 \mathrm{mM}$ Tris pH 7.5, $150 \mathrm{mM} \mathrm{NaCl}, 1 \mathrm{mM} \mathrm{MgCl}_{2}, 1 \mathrm{mM}$ EGTA, $0.5 \mathrm{mM}$ PMSF, $1 \mu \mathrm{M}$ aprotinin, $1 \mu \mathrm{M}$ leupeptin, $1 \mu \mathrm{M}$ pepstatin, $50 \mu \mathrm{M} \mathrm{NaF}, 1 \mu \mathrm{M} \mathrm{NaVO}_{4}, 1 \mu \mathrm{M}$ $\mu$-glycerophosphate) and left on ice for 5 mins. Cell lysates were centrifuged at 13,000 rpm at $4^{\circ} \mathrm{C}$ for 5 mins and the post-centrifugation supernatants collected, mixed with $6 \times$ Laemmli buffer (Invitrogen) and stored at $-20^{\circ} \mathrm{C}$. 
To immunoprecipitate extracellular released Imood, $5 \mu$ of rabbit polyclonal antibody against Tdrp (Novusbio; catalogue number NBP1-93675) and $35 \mu$ l of protein $\mathrm{A} / \mathrm{G}$ sepharose beads (Santa Cruz) were added to $500 \mu 1$ of culture supernatants obtained from $1 \times 10^{7} / \mathrm{ml} \mathrm{CD}^{+} \mathrm{T}$ cells stimulated with plate-bound anti-CD3/CD28 $(1 \mu \mathrm{g} / \mathrm{ml})$ for $24 \mathrm{hrs}$. Samples were incubated overnight at $4^{\circ} \mathrm{C}$ under continuous rotation and then washed with cold PBS for 3 times. Soon after the washes, samples were denatured with $35 \mathrm{ml}$ of $6 \times$ Laemmli buffer (Invitrogen).

Lysates and immunoprecipitates were subjected to electrophoresis on SDS-12\% polyacrylamide gel (Novagen). After subsequent transfer onto polyvinylidene difluoride Immobilon-P Transfer membranes (Millipore, Watford, UK), these were incubated overnight with antibodies diluted in Tris-buffered saline solution containing Tween-20 (TTBS: $130 \mathrm{mM} \mathrm{NaCl} ; 2.68 \mathrm{mM} \mathrm{KCl} ; 19 \mathrm{mM}$ Tris-HCl; 0.001\% v/v Tween-20, pH 7.4) with $5 \%$ nonfat dry milk (Marvel) at $4{ }^{\circ} \mathrm{C}$. Immunoblotting and visualization of proteins by enhanced chemiluminescence (ECL; Amersham Biosciences, Piscataway, NJ, USA) were performed according to manufacturer's instructions. The recombinant Tdrp used as positive control was purchased from Origene (https://www.origene.com; Recombinant protein of human chromosome 8 open reading frame 42 (C8orf42), catalogue number TP313199).

\section{Genetic Immunization}

Genetic immunization is an antibody generation platform offered as service by Aldveron (http://www.aldevron.com). This technology is most suitable to generate neutralising antibodies because native proteins are expressed in vivo with normal posttranscriptional modifications. The target is cloned into one of Aldveron proprietary immunization vectors and introduced into the host organism for gene expression. To help identify positive antisera and hybridomas, screening without purified antigen is made possible with the use of Aldveron proprietary screening vectors.

The procedure followed for the generation of $1 \mathrm{~B} 10$ and $1 \mathrm{C} 4$ is herein briefly described. Six rats were immunised with the immunisation vector $\mathrm{pB} 8$-TDRP-mur containing TDRP cDNA sequence. The immune serum was taken at day 24 of the immunisation protocol, after 4 genetic applications. Sera, diluted in PBS 3\% FBS, were tested by flow cytometry using mammalian cells transiently transfected with the murine Tdrp cDNA cloned into an Aldevron proprietary expression vector (pB1-TDRP-mur). A goat anti-rat IgG Rphycoerythrin conjugate (Southern Biotech, \#3030-09) at $10 \mu \mathrm{g} / \mathrm{ml}$ was used as a secondary antibody. As negative control, mammalian cells transfected with an irrelevant cDNA cloned in the same expression vector were used. Cell surface expression of the screening vector pB1-TDRP-mur was analysed by flow cytometry using an anti-tag antibody and a goat anti-mouse IgG R-phycoerythrin conjugate (Southern Biotech, \#1030-09) at $10 \mu \mathrm{g} / \mathrm{ml}$ as a secondary antibody.

\section{Subjects}


23 OCD outpatients of either gender and any age, treated and followed up at the OCD tertiary outpatient Clinic of the University Department of Psychiatry of Milan, Policlinico Hospital, were included in the study. Diagnoses were assessed by the administration of a semi-structured interview based on DSM-5 criteria (SCID 5 research version, RV). In case of psychiatric comorbidity, OCD had to be the primary disorder, causing the most significant distress and dysfunction and providing the primary motivation to seek treatment. Patients were excluded from the study if they had recent or current alcohol or substance abuse (last 3 months), as well as medical conditions including autoimmune diseases, due to their potential influence over gene expression. For the same reason, lifetime history of trauma (according to DSM-5), as well as the current presence of relevant psychological stress, were considered exclusion criteria. Clinical assessment included the collection of the following demographic and clinical variables: gender, age, age at onset, and current pharmacological treatment. In addition, illness severity was measured through the Yale-Brown Obsessive-Compulsive Scale. Patients had maintained their pharmacological treatment stable for at least one month in order to be enrolled in the study and on the day of collection of blood. Control subjects $(n=20)$ were volunteers matched for gender, age and ethnicity, with no psychiatric diagnosis as determined by the SCID 5 and no positive family history for major psychiatric disorders in the first-degree relatives (as assessed by the Family Interview for Genetic Studies). Blood collection was performed between 2 and $4 \mathrm{pm}$ from fasting donors. PBMCs were separated by density gradient using the Lympholyte-H kit as recommended by the manufacturer (Cedarlane Laboratories, Canada). All subjects had given their written informed consent to participate to the study, which included the use of personal and clinical data as well as blood drawing for genotyping and methylation analysis. The study protocol had been previously approved by the local Ethics Committee.

\section{Statistics}

According to the nature of the data obtained, a Student's $t$ test (2-tailed), or a 1 or 2-way analysis of variance (ANOVA) was performed. Time-course observations were analysed with two-way ANOVA followed by Bonferroni multiple-comparison test. Behavioural data was analysed via nonparametric analysis using the Mann-Whitney $U$ test. All statistical analysis was performed using GraphPad PRISM software v8.0, with the exception of microarray analysis which was carried out as stated in 2.13.3 using the software package LIMMA (Bioconductor). Data was analysed for normality using the D'Agostino-Pearson omnibus normality test.

\section{Results}

\section{Generation and phenotypic characterization of $T$ cell specific AnxA1 ${ }^{\text {tg }}$ mice}

We generated $T$ cell specific transgenic mice through pronuclear injection of VACD2 AnxA1 FLAG construct in 129 FVB mice (Supplementary Figure 1). Both the two founders and their litters showed no gross sign of disease. Following backcrossing onto C57BL/ 6 background and intercross to generate mice with the transgene on both alleles, we noticed that the female litters from one of the two transgenic founders presented an unusual high incidence (almost $80 \%$ ) of maternal cannibalism. This was successfully controlled by administering perphenazine $(0.025 \mathrm{mg} / \mathrm{ml}$ in drinking water $)$ during 
pregnancy as it has been previously reported for other autoimmune prone and highly anxious mouse strains such as the DBA/2J (Carter et al., 2002). Rescued newborn pups from this line (called 'the red line') had often to be raised by C57BL/6 foster mothers to avoid losing the colony. The combined administration of perphenazine and fostering care, made this line challenging to use. Therefore, unless otherwise stated, all the experiments were carried out using the litters of the other founder. Analysis of the immune repertoire of AnxA1 ${ }^{\text {tg }}$ mice from both founders showed no significant differences in lineage commitment towards $\mathrm{CD}^{+}$or $\mathrm{CD}^{+}$cells in all lymphoid organs (Supplementary Figure 1A). To assess if AnxA1 overexpression in $T$ cells would have any effects on the cellularity of the lymphoid organs we measured the total cell number of cells present in lymph nodes, spleen and thymus of AnxA1 ${ }^{\text {tg }}$ mice compared to control. As shown in Supplementary Figure 1B, no significant changes were found except in in lymph nodes where the cellularity was significantly higher (by about 60\%) in AnxA1 ${ }^{\text {tg }}$ mice compared to control.

\section{Increased $T$ cell activation and autoimmunity in $A n x A 1^{\text {tg }}$ mice}

Consistent with our previous reports (D'Acquisto et al., 2007a; D'Acquisto et al., 2007b; Paschalidis et al., 2010; Paschalidis et al., 2009) AnxA1 ${ }^{\text {tg }}$ T cells showed a clear proinflammatory phenotype as evidenced by lower threshold of CD25 and CD69 upregulation (Figure 1A) and increased production of IL-2 following anti-CD3 plus anti-CD28 (antiCD3/CD28) stimulation (Figure 1B). In vivo, AnxA1 ${ }^{\text {tg }}$ mice showed an exacerbated inflammatory response in the $\mathrm{MOG}_{35-55}$-induced experimental autoimmune encephalomyelitis (EAE) (Figure 1C) as evidenced by the exacerbated severity of the clinical score and increased weight loss after the onset of the disease (day 12) and larger inflammatory infiltrate of the spinal cord in AnxA1 ${ }^{\text {tg }}$ mice compared to wild type. No differences were observed in terms of disease incidence between control and AnxA1 ${ }^{\text {tg }}$ mice (Table in Figure 1C). The same exacerbated inflammatory response was observed and confirmed in the red line mice (Supplementary Figure 3A). To expand and confirm these findings in another model of autoimmune inflammation, we subjected AnxA1 ${ }^{\text {tg }}$ mice to an experimental model of systemic lupus erythematosus (Reeves et al., 2009). As shown in Figure 1D (right panel), injection of pristane to AnxA1 ${ }^{\text {tg }}$ mice provoked a significant weight loss over a period of 35 days while control mice gained about $30 \%$ of their initial weight over the same period. As the disease progresses, a number of organs, including the spleen and the lung, becomes enlarged or accumulate inflammatory infiltrate (Chowdhary et al., 2007; Freitas et al., 2017). As shown in Supplementary Figure 4A, AnxA1 ${ }^{\text {tg }}$ mice showed increased splenomegaly (spleen weight $0.130 \pm 0.010$ gr in wild type mice vs $0.281 \pm 0.011$ gr in AnxA1 ${ }^{\text {tg}}$; $n=5$ mice, $p<0.0001$ ) with typical pathological features such as enlarged B-cell follicles and infiltration of oil droplets compared to control wild type mice. The lungs of AnxA1 tg mice also showed increased areas of focal hemorrhages together with severe mixed inflammatory infiltrate compared to control (Supplementary Figure 4B). Consistent with these results, $\sim 30 \%$ of AnxA1 ${ }^{\text {tg }}$ mice died during the 35-day treatment while control animals showed a 100\% survival (Figure 1D; left panel).

Selective accumulation of Th1/Th17 double positive cells in the inflamed tissue of AnxA1 $1^{\text {tg }}$ mice 
To further examine the activation state of AnxA1 $1^{\text {tg }} \mathrm{T}$ cells in the EAE mice, we investigated the effector phenotype of these cells at day 9 (onset of the disease) and day 16 (peak of the disease). This allowed us to distinguish the effects of AnxA1 overexpression during the priming phase occurring in the draining lymph nodes at day 9 or the differentiation phase occurring within the spinal cord at day 16 (Rossi and Constantin, 2016). Comparison of the total cell number of $\mathrm{CD} 45^{+}$leukocytes in either lymph node or spinal cord of AnxA1 ${ }^{\text {tg }}$ and wild type mice showed no significant differences (Figure 2A and B, bottom panels). Day 9 comparison of the draining lymph nodes of control and AnxA1tg mice showed a significant increase in the number of $\mathrm{CD}^{+}{ }^{+} \mathrm{T}$ cells (by about $85 \%$ ) in the latter group, but no difference in the percentage of IL- $17^{+} / \mathrm{IFN}-\gamma^{+}$or $\mathrm{IL}-17^{+} /$ $\mathrm{GM}^{-\mathrm{CSF}^{+}}$double-positive or single-positive T cells (Figure 2A). At day 16, the number of $\mathrm{CD}^{+} \mathrm{T}$ cells recovered from the spinal cord of was $\sim 3$-fold higher in AnxA1 ${ }^{\text {tg }}$ compared to control but in this case we observed an increase in the percentages of IFN- $\gamma^{+} /$ $\mathrm{IL}_{-1} 7^{+}\left(1.9 \pm 0.12 \%\right.$ in wild type vs $4.5 \pm 0.21 \%$ in AnxA1 ${ }^{\mathrm{tg}}$; $\left.\mathrm{n}=6, \mathrm{p}<0.0001\right)$ or GM$\mathrm{CSF}^{+} / \mathrm{IL}_{-1} 7^{+}(4.8 \pm 0.19 \%$ in wild type vs $10.4 \pm 0.45 \%$ in AnxA1tg; $\mathrm{n}=6, \mathrm{p}<0.0001)$ pathogenic (DuPage and Bluestone, 2016) double-positive T cells in the former compared to the latter (Figure 2B). Fate mapping reporter studies for Th17 cells in this model of autoimmune inflammation have shown that these double-positive cells represent a transition phase during the 'conversion' of IL-17 single-positive into IFN- $\gamma$ or GM-CSF double-positive $T$ cells at the site of inflammation (Hirota et al., 2011). Consistent with these findings, AnxA1tg mice show a higher percentage of $\mathrm{IL}-17^{+}$cells and a corresponded reduced percentage of IFN- $\gamma$ (about $10 \%$ in AnxA1tg $v s 18 \%$ in control) and GM-CSF (about $16 \%$ in AnxA1 ${ }^{\text {tg }}$ vs 20\% in control) single-positive cells (Figure 2B).

\section{Increased basal anxiety-like behavior in AnxA1 ${ }^{\text {tg }}$ mice}

Direct observation of AnxA1 ${ }^{\text {tg }}$ mice in their cage revealed an altered behavior typified by an increased tendency to compulsive digging (compare Movie 1, wild type mice and Movie 2, AnxA1 tg mice). Similar behavior was observed in the litters from the other founder (red line mice; compare Movie 3 of wild type mice with Movie 4 of AnxA1 $1^{\text {tg }}$ mice). Interestingly, the litter of red line mice also showed an increased level of heterobarbering (plucking of fur from cage-mates; Movie 5) - a behavior that has been proposed to represent a model of human trichotillomania and obsessive-compulsive spectrum disorders (Garner et al., 2004). To thoroughly measure this heightened anxious behavior, we used a battery of classical tests for anxiety behavior. The marble-burying test is used to measure digging (Taylor et al., 2017) and when applied to AnxA1 ${ }^{\text {tg }}$ we quantified a significant increase in the number of buried marbles by the mice, which spent approximately double the time on this activity (Figure 3A). In the light and dark shuttle box test (Bourin and Hascoet, 2003) AnxA1 ${ }^{\text {tg }}$ mice spent in the lit area than the wild type counterpart, with a marked attenuation of numbers of crossings between the two compartments (Figure 3B). Significant behavioral differences were observed also in the climbing test- an experimental paradigm to measure vertical activity (Deacon and Rawlins, 2005) AnxA1 ${ }^{\text {tg }}$ mice showed an increased latency to the first climb and a significant reduction in the time spent on this activity (Figure 3C). All these changes were not secondary to a general impairment of locomotor activity as AnxA1 ${ }^{\text {tg }}$ mice showed no difference in the number of i) square crossed or ii) rearing as quantified in the open field test (Brooks and Dunnett, 2009) when compared to wild type animals (Figure 3D). This 
heightened anxiety-like behavior was confirmed in the litters of the red line mice (Supplementary Figure 3B).

\section{Gene fingerprint of AnxA1 ${ }^{\text {tg }}$ whole brain reveals an increased expression of anxiety- related genes}

$\mathrm{CD}^{+} \mathrm{T}$ cells exert a homeostatic control over a number of functions of the brain including learning, memory and anxiety-like behavior (Filiano et al., 2016). In a previous study we have shown that $\mathrm{CD}^{+}$rather than $\mathrm{CD}^{+} \mathrm{T}$ cells revert the increased anxiety-like behavior observed in Rag-1 $1^{-/}$immunodeficient mice. Most interestingly, we have shown that the modulatory effects exerted by $\mathrm{CD}^{+} \mathrm{T}$ cells on behavior were 'mirrored' by specific changes in the gene fingerprint of the whole brain (Rattazzi et al., 2013). Thus, for instance, S100a10, a known biomarker for anxiety-like behavior, was up-regulated in RAG-1/- and down-regulated to wild type level in $\mathrm{RAG}-1^{-/-}$mice where $\mathrm{CD}^{+} \mathrm{T}$ cells artificially re-introduced (RAG-1\%-/OT-II TCR transgenic mice). In light of these premises, we queried if AnxA1 ${ }^{\text {tg }}$ mice would also show changes in their brain gene fingerprint and performed a comparative analysis of gene expression of the whole brain using microarray analysis. The results showed significant differences in the level of expression of 15 genes of which 8 were unregulated and 7 downregulated in the whole brains of AnxA1 $1^{\text {tg }}$ mice in comparison to those of wild type mice (Figure $4 \mathbf{A}$ and Supplementary Table 1). Among these, several were associated with emotional disorders including alcoholism and anxiety such as erythroid differentiation regulator 1 (Erdrl) (Hovatta et al., 2005) and gamma-aminobutyric acid receptor subunit alpha-2 (Gabra2) (Engin et al., 2012) (Figure 4B) RT-PCR analysis of these genes on a larger number of samples confirmed these results with a down regulation of Erdrl by about $78 \%$ and an $\sim 3$-fold upregulation of Gabra 2 (Figure 4C). Thus, the transgenic T cells can exert a tonic regulation on a discrete set of genes in the brain, even in the absence of any experimental manipulation.

\section{AnxA1 $^{\text {tg }} \mathrm{CD4}^{+} \mathrm{T}$ cells express high level of a new anxiogenic factor named Immuno- moodulin}

To identify the anxiogenic factor produced by AnxA1tg CD4 $4^{+} \mathrm{T}$ cells, we compared gene expression profiles of purified $\mathrm{CD}^{+} \mathrm{T}$ cells by microarray. In resting conditions, no statistical differences were observed between AnxA1 ${ }^{\text {tg }}$ and control CD4 ${ }^{+} \mathrm{T}$ cells (data not shown). However, in anti-CD3/CD28 stimulated cells, 8 genes were identified to be significantly modulated (Supplementary Table 2). Among those upregulated, AnxA1, interferon-inducible 203 and 2610019F03Rik (also called testis development related protein, Tdrp or C8orf42). We were intrigued by the last one as it encoded for a small protein of about $21 \mathrm{kDa}$ (like most of the cytokines) that was stored in vesicles (https:// www.proteinatlas.org/ENSG00000180190-TDRP/cell) and present in circulation (https:// genecards.weizmann.ac.il/v3/cgi-bin/carddisp.pl?gene=TDRP) and therefore decided to investigate its function. As we identified this gene in $\mathrm{T}$ cells and hypothesized that would be responsible for the anxious behavioral phenotype of AnxA1 ${ }^{\text {tg }}$ mice, we named it Immuno-moodulin (Imood).

Next, we validated microarray results using immunoblotting and FACS intracellular staining of $\mathrm{CD}^{+} \mathrm{T}$ cells using a commercially available polyclonal antibody against 
Imood. We first investigated Imood expression in resting or activated $\mathrm{T}$ cells from nontransgenic C57BL/ 6 mice. In basal conditions, about $20 \%$ of cells express high levels of Imood. Activation of $\mathrm{CD}^{+} \mathrm{T}$ cells via the TCR caused a clear increase in the number of these cells with a doubling of their number (44\%) following the triggering of both signal 1 (anti-CD3) and signal 2 (anti-CD28) (Figure 5A). When we compared the expression of Imood in resting wild type and AnxA1 ${ }^{\text {tg }} \mathrm{CD}^{+} \mathrm{T}$ cells (Figure 5B), it was possible to see an increase in the percentages of Imood-high cells in AnxA1 ${ }^{\text {tg }}$ mice compared to wild type (about 55\% in AnxA1tg vs 35\% in wild type) and their median fluorescence intensity (about 15 in AnxA1 ${ }^{\text {tg }}$ vs 7 in wild type). These differences tapered off but remained visible following activation with anti-CD3/CD28: about $80 \%$ of AnxA1 ${ }^{\text {tg }}$ cells expressed Imood with a median fluorescence intensity of 26 while about $70 \%$ wild type cells showed a median of 18. These results were confirmed at mRNA levels where it was possible to observe both the upregulation of Imood mRNA following activation of T cells with anti$\mathrm{CD} 3 / \mathrm{CD} 28$ and an increased expression in AnxA1 ${ }^{\text {tg }}$ compared to wild type in both resting and stimulating conditions (Figure 5C). We confirmed these findings by western blot. Resting AnxA1 ${ }^{\text {tg }} \mathrm{CD}^{+} \mathrm{T}$ cells showed increased levels of intracellular Imood compared to control (Figure 6D, Top panel). In addition, immunoprecipitation of Imood from the cell supernatant of wild type and AnxA1 ${ }^{\text {tg }} \mathrm{T}$ cells in both resting and activated conditions showed an increased secretion of this protein in AnxA1 ${ }^{\text {tg }} \mathrm{T}$ cells (Figure 5D, bottom panel).

To explore the possible role of Imood in regulating anxiety behavior we administered the recombinant product of this gene (https://www.origene.com; Recombinant protein of human chromosome 8 open reading frame 42 [C8orf42], catalogue number TP313199) into wild type C57BL/6 mice. In all the experiments that followed, we used the light-dark shuttle box as a convenient screening test since this showed the highest difference between AnxA1 ${ }^{\text {tg }}$ and wild type mice. As shown in Supplementary Figure 5, mice injected with $500 \mathrm{ng}$ of the intact (r-Imood) but not the denatured $\left(95^{\circ} \mathrm{C}\right.$ for $\left.5 \mathrm{~min}\right)$ protein $(\mathrm{d}-\mathrm{Imood})$ or PBS showed a significant increase in anxiety-like behavior. This change did not occur within hours of administration but started to be noticeable at day 3 post-injection (data not shown) and became highly significant at day 7. To confirm that Imood was indeed responsible for the increased anxiety-like behavior of AnxA1 tg mice, we administered a commercially available polyclonal antibody against this protein (https:// www.novusbio.com/; catalogue number NBP1-93675) and control IgG to these mice. We also administered the same dose of antibodies and control IgG to wild type C57BL/6 to test its effect in control mice. As shown in Supplementary Figure 6, only AnxA1 ${ }^{\text {tg }}$ mice that received the polyclonal anti-Imood antibodies but not those receiving the control IgG showed a significant increase of the time in the light (by $\sim 249 \% ; p<0.001$ ) and number of crossing (by $\sim 194 \%$; $<<0.001$ ). Interestingly, administration of the same antibody in wild type C57BL/6 mice also caused a significant increase in time in the light (by $\sim 24 \%$; $\mathrm{p}<0.05$ ) and number of crossing (by $\sim 76 \%$; $<0.01$ ) suggesting there may be an endogenous Imood level which might regulate basal anxiety behavior of mice.

To further validate our hypothesis and increase specificity of action, we generated monoclonal antibodies against Imood using genetic immunization (Bates et al., 2006) (Supplementary Figure 7). Congruent with previous data, administration of highly 
selective purified monoclonal anti-Imood antibodies $1 \mathrm{~B} 10$ or $1 \mathrm{C} 4$ to AnxA1 ${ }^{\text {tg }}$ significantly increased the number of crossing (by $\sim 123 \%, \mathrm{p}<0.01$ for $1 \mathrm{C} 4$; by $\sim 178 \%, \mathrm{p}<0.001$ for $1 \mathrm{~B} 10$ ) and the time in the light (by $\sim 208 \%, \mathrm{p}<0.01$ for $1 \mathrm{C} 4$; by $\sim 396 \%, \mathrm{p}<0.001$ for $1 \mathrm{~B} 10$ ) compared to $\mathrm{IgG}$ control. Thus, anti-Imood therapy rescues the phenotype of AnxA1 $1^{\text {tg }}$ back to that of wild type mice.

Similar to what we observed with the polyclonal antibody, C57BL6 control mice administered with $1 \mathrm{~B} 10$ and $1 \mathrm{C} 4$ showed significant increase in time in the light (by $\sim 75 \%, \mathrm{p}<0.01$ for $1 \mathrm{C} 4$; by $\sim 86 \%, \mathrm{p}<0.001$ for $1 \mathrm{~B} 10$ ) and number of crossings (by $\sim 41 \%$, $\mathrm{p}<0.05$ for $1 \mathrm{C} 4$; by $\sim 68 \%, \mathrm{p}<0.001$ for $1 \mathrm{~B} 10$ ). Collectively this data reveals Imood as an innovative target for therapeutic strategies to treat anxiety behavior in mice (Figure 6A).

\section{Increased expression of Imood in OCD patients}

Finally, we searched for Imood expression in man. To this aim, we performed an initial retrospective screening of cDNA samples of PBMC obtained from obtained from 23 patients that have been diagnosed with Obsessive-Compulsive Disorders and 20 healthy controls. Both sociodemographic (gender, education, employment and marital status) and clinical (duration of illness, duration of untreated illness, family history of psychiatric disorders, psychiatric comorbidity and current treatments) variables have been reported in

Supplementary Table 3. As shown in Figure 6B, Imood expression was significantly higher (approximately 6-fold) than controls in both male and female subjects.

\section{Discussion}

A growing number of studies support the hypothesis that mood disorders can be driven by cellular and biochemical events that are rooted in the immune system (Dantzer, 2018; Haroon et al., 2012; Miller et al., 2017). This evidence emerged from several experimental studies investigating how both the depletion of T cells in mice (Cohen et al., 2006; Wolf et al., 2009) or the repopulation of lymphopenic mice with $\mathrm{T}$ cells alter brain functions including cognitions (Brynskikh et al., 2008; Kipnis et al., 2004), fear (Clark et al., 2014) and emotional states (Laumet et al., 2018; Rattazzi et al., 2013). Thus, in a study by Clark et al., CD4 ${ }^{+} \mathrm{T}$ cells conferred anxiolytic and antidepressant-like effects in Rag-2-/ mice (Clark et al., 2016). Using similar approaches, Brachman et al. and Scheinert et al. have shown that adoptive transfer of lymph node cells from chronically stressed mice were able to revert the anxious and depressive-like behavior of Rag-2-/- mice (Brachman et al., 2015; Scheinert et al., 2016).

The modulatory effect of $\mathrm{T}$ cells on behavior has also been explored using effector disease relevant $\mathrm{T}$ cells. Seminal studies by Beurel and Jope have shown that the number of effector Th17 cells was significantly higher in the brain of mice exhibiting depressive-like behavior or in mice subjected to chronic restraint stress (Beurel et al., 2013; Beurel and Lowell, 2018; Beurel et al., 2018). In line with the studies mentioned above, the same group has shown that adoptively transferred Th17 cells in Rag-2/- mice accumulated in the hippocampus of learned-helpless mice (Beurel et al., 2013). This work has provided key evidence that autoimmune effector $\mathrm{T}$ cells play a fundamental role in regulating pathological processes other than autoimmunity. In the context of this study, these findings have laid the foundations for a further exploration of the possible mechanisms linking autoimmunity and mental disorders. In addition, the lack of novel therapeutic 
opportunities to treat mental health issues is very topical and we reason that detailed investigation of the mechanism(s) linking the immune system with behavioral responses could guide the development of new therapies.

We reasoned about the existence of novel mechanism and plausibly un-identified factors while noting the behavioral phenotype of mice which single anomaly was higher expression of AnxA1 in T cells. This transgenic tool was generated to further investigate the specific properties of this mediator on the adaptive immune response (D'Acquisto, 2009; D'Acquisto et al., 2007a; D'Acquisto et al., 2007b). In retrospective, our novel observations are aligned with the emerging notion that AnxA1 can regulate mental disorders. Genome-Wide Association Studies searches (GWAS Central at www.gwascentral.org) for AnxA1 reported about 62 studies on this protein and many of them on mental disorders. In fact, reports have shown a significant association between AnxA1 gene duplication and autism (Correia et al., 2014) or single nucleotide polymorphism in AnxA1 gene and schizophrenia(Clark et al., 2006) bipolar disorder or depression(Huang et al., 2010). Most intriguingly, all these conditions have been often linked to immune dysfunctions or inflammatory conditions (Muller, 2017; Prata et al., 2017; Severance et al., 2018).

Moreover, AnxA1 is a ligand for the formyl peptide receptors (FPRs) (Bena et al., 2012; Cooray et al., 2013; Pederzoli-Ribeil et al., 2010). These prototype sensors of the innate immune system were initially identified as the cellular antenna for the capture of formylated peptides released by bacterial pathogens (Chen et al., 2017; Lee et al., 2017; Migeotte et al., 2006; Winther et al., 2018). Of interest, studies have shown that these receptors have more than one way to help the host sensing the danger. Their expression in the olfactory system allow mice to 'sense' the presence of infection-associated olfactory cues thus allowing animals to move away from the source of infection (Ackels et al., 2014; Bufe et al., 2012; Stempel et al., 2016). Other lines of evidence support a role for FPR in regulating behaviour. Studies in knock out mice for both FPR1 and FPR2/ALX receptors have shown a significant reduction in anxiety (Gallo et al., 2014; Gao et al., 2011) e.g. the opposite phenotype of AnxA1 tg mice. Putting everything together, FPR may represent a prototype of signalling molecules that influence the behaviour of the host at both cellular and physical levels with the ultimate goal of preserving it from the challenges of the external environments (Dietschi et al., 2017).

The anxiolytic effects of antibodies against Imood required days to be visible and statistically significant. A similarly delayed response was observed with recombinant Imood suggesting, in both cases, a downstream regulation of the expression of genes associated to anxiety rather than influencing directly the effects of neurotransmitters in the brain. The time-lag effect for the emergence of modulatory effects on anxiety, with AnxA1 ${ }^{\text {tg }}$ cells or following the administration of Imood, resonates well with the notion that classical drugs for the treatment of depression and anxiety present a delayed onset of 5 to 7 days for their clinical efficacy to be apparent (Lam, 2012). Recent studies have put forward the proposition that delayed onset could be linked to the time needed for the immune system to respond and/or adapt to the administration of these drugs (KiecoltGlaser et al., 2002), reinforcing the hypothesis that the immune system regulates the emotional state via a homeostatic control of the expression of genes with direct effect on emotions. 
Our study opens a number of interesting and challenging questions that needs to be addressed. The first studies on Tdrp indicated a primary role in spermatogenesis (hence the name testis development-related protein) (Wang et al., 2010). However, further studies have shown that Tdrp-deficient mice were not significantly different from wild-type littermates in the development of testes, genitourinary tract, or sperm count. Tdrp deficiency alone was not sufficient to cause male infertility in mice (Mao et al., 2016). Consistent with this, administration of 1B10 and 1C4 in mice did not show any effects on male mice fertility or number of spermatocytes (data not shown). Combining all this information, it is possible to speculate that the protein has biological effects other than regulating spermatogenesis. At this regard, a very interesting study has recently shown that Tdrp is linked to mental disorders, including Attention-Deficit/Hyperactivity Disorder (ADHD) (Harich et al., 2019). The authors sought to validate the relevance of their finding in Drosophila but while they could find two orthologues for FBXO25, there was no orthologue for Tdrp. As Drosophila does not have an adaptive immune system, it is tempting to speculate that indeed Tdrp (Imood) might be a genuine 'peripheral' modulator of anxiety behaviour that is expressed in T cells. This is a rather interesting hypothesis that is corroborated by the fact that - to the best of our knowledge - Imood is not expressed in any invertebrate which are known to lack an adaptive immune system.

This study provides solid foundations for future clinical and experimental work aimed at understanding how Imood might ultimately influence behavior. First of all, we would need to establish how Imood would enter the brain and what would be its receptor(s). Paradigmshifting work by Kipnis and collaborators have very recently ascribed the meningeal lymphatic as "a system capable of carrying fluid, immune cells, and macromolecules from the central nervous system" (Raper et al., 2016). This system has been proposed as the vascular network that allows the circulation and exchange of soluble contents between the brain cerebrospinal fluid and interstitial fluid (Da Mesquita et al., 2018; Herz et al., 2018) and could be therefore the entry door for Imood in the CNS.

Another interesting perspective would be the existence of an Imood-specific mechanics of transport present in epithelial cells of the choroid plexus and in endothelial cells of the blood-brain barrier like in the case of leptin (Zlokovic et al., 2000). One surprising finding of our study is the existence of a small percentage of $\mathrm{CD}^{+} \mathrm{T}$ cells expressing high levels of Imood (Figure 6) and the increased number of these cells in the AnxA1 ${ }^{\text {tg }}$ mice. As transgenic mice are an experimental system that is artificially created to test a hypothesis, it will be very important in the future to confirm these findings in clinical samples and to further characterize and track these Imood-high T cells. Indeed, it is tempting to speculate that these Imood-high cells could specifically recirculate through the brain and thus be directly involved in the regulation of brain gene expression profile. This would be particularly intriguing as we have observed a readily upregulation of this protein following TCR stimulation. The constitutive activation state of autoimmune $\mathrm{T}$ cells might justify, at least in part, the increased incidence of mental disorders in patients suffering these diseases. All these hypotheses could only be validated through systematic screening for Imood expression at both protein and mRNA levels in a large cohort of patients, with different types of mental disorders as well. 
The possibility that Imood could represent a novel fine tuner of mental disorders would also offer the opportunity to have a novel biomarker of prognostic and diagnostic value. This would enable patient stratification for the correct mental disorder (e.g. those associated with an immune component) or identification of the right patient subgroup for specific drug treatment. As such, for those with higher expression of Imood, a combinatorial therapy with immunomodulators and Imood neutralizing antibodies like 1B10 might provide the unique opportunity to achieve a 'healthy body in a healthy mind'. Along these lines, the identification of a protein mediator of emotional behavior and the availability of biological therapies that modulate its levels would represent a significant step forward for the treatment of mental disorders. Indeed, a biologic for the treatment of mental disorder would bypass several of the side effects associated with the daily administration of standard therapies mental disorders (Babic et al., 2010; Serretti and Chiesa, 2011; Uzun et al., 2010) as it would specifically act at the level of immune system rather than the CNS.

\section{Acknowledgments}

Funding: This study was supported by the MRC New Investigator award to FDA, the Arthritis Research UK PhD studentship to NP and Queen Mary University of London Principal's PhD studentship to GP.

Author contributions: NP generated the AnxA1 ${ }^{\text {tg }}$ mice. GP and LR performed all the behavioral and immunological characterization of the AnxA1 ${ }^{\text {tg }}$ mice. SO and GB screened and tested antibodies against Imood. MO analyzed the microarray data. BD recruited OCD patients. CDA and FB assessed Imood expression in OCD patients. CM and MP contributed to the analysis and design of the study. FDA designed the study, analyzed the data, wrote the manuscript and contributed to all the stages of the experimental work.

Data and materials availability: The data that support the findings of this study are available from the corresponding author upon reasonable request.

Acknowledgments. We would like to thank Prof Kioussis for kindly providing us the CD2 cassette plasmid.

Competing interests: The authors declare no conflict of interest.

\section{References and Notes}

Ackels, T., von der Weid, B., Rodriguez, I., Spehr, M., 2014. Physiological characterization of formyl peptide receptor expressing cells in the mouse vomeronasal organ. Front Neuroanat 8, 134. Babic, D., Maslov, B., Martinac, M., Nikolic, K., Uzun, S., Kozumplik, O., 2010. Bipolar disorder and metabolic syndrome: comorbidity or side effects of treatment of bipolar disorder. Psychiatr Danub 22, 75-78.

Bates, M.K., Zhang, G., Sebestyen, M.G., Neal, Z.C., Wolff, J.A., Herweijer, H., 2006. Genetic immunization for antibody generation in research animals by intravenous delivery of plasmid DNA. Biotechniques 40, 199-208. 
Bena, S., Brancaleone, V., Wang, J.M., Perretti, M., Flower, R.J., 2012. Annexin A1 interaction with the FPR2/ALX receptor: identification of distinct domains and downstream associated signaling. J Biol Chem 287, 24690-24697.

Beurel, E., Harrington, L.E., Jope, R.S., 2013. Inflammatory T helper 17 cells promote depression-like behavior in mice. Biol Psychiatry 73, 622-630.

Beurel, E., Lowell, J.A., 2018. Th17 cells in depression. Brain Behav Immun 69, 28-34.

Beurel, E., Lowell, J.A., Jope, R.S., 2018. Distinct characteristics of hippocampal pathogenic TH17 cells in a mouse model of depression. Brain Behav Immun 73, 180-191.

Bosche, K., Weissenborn, K., Christians, U., Witzke, O., Engler, H., Schedlowski, M., Hadamitzky, M., 2015. Neurobehavioral consequences of small molecule-drug immunosuppression. Neuropharmacology 96, 83-93.

Boudhraa, Z., Bouchon, B., Viallard, C., D'Incan, M., Degoul, F., 2016. Annexin A1 localization and its relevance to cancer. Clin Sci (Lond) 130, 205-220.

Bourin, M., Hascoet, M., 2003. The mouse light/dark box test. Eur J Pharmacol 463, 55-65.

Brachman, R.A., Lehmann, M.L., Maric, D., Herkenham, M., 2015. Lymphocytes from chronically stressed mice confer antidepressant-like effects to naive mice. J Neurosci 35, 1530-1538.

Brooks, S.P., Dunnett, S.B., 2009. Tests to assess motor phenotype in mice: a user's guide. Nat Rev Neurosci 10, 519-529.

Brynskikh, A., Warren, T., Zhu, J., Kipnis, J., 2008. Adaptive immunity affects learning behavior in mice. Brain Behav Immun 22, 861-869.

Bufe, B., Schumann, T., Zufall, F., 2012. Formyl peptide receptors from immune and vomeronasal system exhibit distinct agonist properties. J Biol Chem 287, 33644-33655.

Butt, A.A., Evans, R., Skanderson, M., Shakil, A.O., 2006. Comorbid medical and psychiatric conditions and substance abuse in HCV infected persons on dialysis. J Hepatol 44, 864-868.

Carter, D.B., Kennett, M.J., Franklin, C.L., 2002. Use of perphenazine to control cannibalism in DBA/1 mice. Comp Med 52, 452-455.

Chen, K., Bao, Z., Gong, W., Tang, P., Yoshimura, T., Wang, J.M., 2017. Regulation of inflammation by members of the formyl-peptide receptor family. J Autoimmun 85, 64-77. Chomczynski, P., Sacchi, N., 1987. Single-step method of RNA isolation by acid guanidinium thiocyanate-phenol-chloroform extraction. Anal Biochem 162, 156-159.

Chowdhary, V.R., Grande, J.P., Luthra, H.S., David, C.S., 2007. Characterization of haemorrhagic pulmonary capillaritis: another manifestation of Pristane-induced lupus. Rheumatology (Oxford) 46, 1405-1410.

Clark, D., Dedova, I., Cordwell, S., Matsumoto, I., 2006. A proteome analysis of the anterior cingulate cortex gray matter in schizophrenia. Mol Psychiatry 11, 459-470, 423.

Clark, S.M., Sand, J., Francis, T.C., Nagaraju, A., Michael, K.C., Keegan, A.D., Kusnecov, A., Gould, T.D., Tonelli, L.H., 2014. Immune status influences fear and anxiety responses in mice after acute stress exposure. Brain Behav Immun 38, 192-201.

Clark, S.M., Soroka, J.A., Song, C., Li, X., Tonelli, L.H., 2016. CD4(+) T cells confer anxiolytic and antidepressant-like effects, but enhance fear memory processes in Rag2(-/-) mice. Stress 19, 303-311.

Cohen, H., Ziv, Y., Cardon, M., Kaplan, Z., Matar, M.A., Gidron, Y., Schwartz, M., Kipnis, J., 2006. Maladaptation to mental stress mitigated by the adaptive immune system via depletion of naturally occurring regulatory CD4+CD25+ cells. J Neurobiol 66, 552-563. 
Cooray, S.N., Gobbetti, T., Montero-Melendez, T., McArthur, S., Thompson, D., Clark, A.J., Flower, R.J., Perretti, M., 2013. Ligand-specific conformational change of the G-protein-coupled receptor ALX/FPR2 determines proresolving functional responses. Proc Natl Acad Sci U S A 110, 18232-18237.

Correia, C.T., Conceicao, I.C., Oliveira, B., Coelho, J., Sousa, I., Sequeira, A.F., Almeida, J., Cafe, C., Duque, F., Mouga, S., Roberts, W., Gao, K., Lowe, J.K., Thiruvahindrapuram, B., Walker, S., Marshall, C.R., Pinto, D., Nurnberger, J.I., Scherer, S.W., Geschwind, D.H., Oliveira, G., Vicente, A.M., 2014. Recurrent duplications of the annexin A1 gene (ANXA1) in autism spectrum disorders. Mol Autism 5, 28.

Cournos, F., McKinnon, K., Sullivan, G., 2005. Schizophrenia and comorbid human immunodeficiency virus or hepatitis C virus. J Clin Psychiatry 66 Suppl 6, 27-33.

Coutinho, E., Vincent, A., 2016. Autoimmunity in neuropsychiatric disorders. Handb Clin Neurol 133, 269-282.

D'Acquisto, F., 2009. On the adaptive nature of annexin-A1. Curr Opin Pharmacol 9, 521-528.

D'Acquisto, F., Merghani, A., Lecona, E., Rosignoli, G., Raza, K., Buckley, C.D., Flower, R.J., Perretti, M., 2007a. Annexin-1 modulates T-cell activation and differentiation. Blood 109, 1095-1102.

D'Acquisto, F., Paschalidis, N., Sampaio, A.L., Merghani, A., Flower, R.J., Perretti, M., $2007 b$. Impaired T cell activation and increased Th2 lineage commitment in Annexin-1-deficient T cells. Eur J Immunol 37, 3131-3142.

D'Acquisto, F., Piras, G., Rattazzi, L., 2013. Pro-inflammatory and pathogenic properties of Annexin-A1: the whole is greater than the sum of its parts. Biochemical pharmacology 85 , 1213-1218.

Da Mesquita, S., Fu, Z., Kipnis, J., 2018. The Meningeal Lymphatic System: A New Player in Neurophysiology. Neuron 100, 375-388.

Dantzer, R., 2018. Neuroimmune Interactions: From the Brain to the Immune System and Vice Versa. Physiol Rev 98, 477-504.

Deacon, R.M., Rawlins, J.N., 2005. Hippocampal lesions, species-typical behaviours and anxiety in mice. Behav Brain Res 156, 241-249.

Dietschi, Q., Tuberosa, J., Rosingh, L., Loichot, G., Ruedi, M., Carleton, A., Rodriguez, I., 2017. Evolution of immune chemoreceptors into sensors of the outside world. Proc Natl Acad Sci U S A 114, 7397-7402.

DuPage, M., Bluestone, J.A., 2016. Harnessing the plasticity of CD4(+) T cells to treat immunemediated disease. Nat Rev Immunol 16, 149-163.

Engin, E., Liu, J., Rudolph, U., 2012. alpha2-containing GABA(A) receptors: a target for the development of novel treatment strategies for CNS disorders. Pharmacol Ther 136, 142-152.

Feinstein, A., Pavisian, B., 2017. Multiple sclerosis and suicide. Mult Scler 23, 923-927.

Filiano, A.J., Xu, Y., Tustison, N.J., Marsh, R.L., Baker, W., Smirnov, I., Overall, C.C., Gadani, S.P., Turner, S.D., Weng, Z., Peerzade, S.N., Chen, H., Lee, K.S., Scott, M.M., Beenhakker, M.P., Litvak, V., Kipnis, J., 2016. Unexpected role of interferon-gamma in regulating neuronal connectivity and social behaviour. Nature 535, 425-429.

Freitas, E.C., de Oliveira, M.S., Monticielo, O.A., 2017. Pristane-induced lupus: considerations on this experimental model. Clin Rheumatol 36, 2403-2414.

Gallo, I., Rattazzi, L., Piras, G., Gobbetti, T., Panza, E., Perretti, M., Dalley, J.W., D'Acquisto, F., 2014. Formyl peptide receptor as a novel therapeutic target for anxiety-related disorders. PLoS

One 9, e114626. 
Gao, J.L., Schneider, E.H., Dimitrov, E.L., Haun, F., Pham, T.M., Mohammed, A.H., Usdin, T.B., Murphy, P.M., 2011. Reduced fear memory and anxiety-like behavior in mice lacking formylpeptide receptor 1. Behav Genet 41, 724-733.

Garner, J.P., Weisker, S.M., Dufour, B., Mench, J.A., 2004. Barbering (fur and whisker trimming) by laboratory mice as a model of human trichotillomania and obsessive-compulsive spectrum disorders. Comp Med 54, 216-224.

Goeb, J.L., Even, C., Nicolas, G., Gohier, B., Dubas, F., Garre, J.B., 2006. Psychiatric side effects of interferon-beta in multiple sclerosis. Eur Psychiatry 21, 186-193.

Guo, C., Liu, S., Sun, M.Z., 2013. Potential role of Anxa1 in cancer. Future Oncol 9, 1773-1793. Harich, B., Klein, M., Ockeloen, C.W., van der Voet, M., Schimmel-Naber, M., de Leeuw, N., Schenck, A., Franke, B., 2019. From man to fly - convergent evidence links FBXO25 to ADHD and comorbid psychiatric phenotypes. J Child Psychol Psychiatry.

Haroon, E., Raison, C.L., Miller, A.H., 2012. Psychoneuroimmunology meets neuropsychopharmacology: translational implications of the impact of inflammation on behavior. Neuropsychopharmacology 37, 137-162.

Herz, J., Louveau, A., Da Mesquita, S., Kipnis, J., 2018. Morphological and Functional Analysis of CNS-Associated Lymphatics. Methods Mol Biol 1846, 141-151.

Hirota, K., Duarte, J.H., Veldhoen, M., Hornsby, E., Li, Y., Cua, D.J., Ahlfors, H., Wilhelm, C., Tolaini, M., Menzel, U., Garefalaki, A., Potocnik, A.J., Stockinger, B., 2011. Fate mapping of IL-17-producing T cells in inflammatory responses. Nat Immunol 12, 255-263.

Hovatta, I., Tennant, R.S., Helton, R., Marr, R.A., Singer, O., Redwine, J.M., Ellison, J.A., Schadt, E.E., Verma, I.M., Lockhart, D.J., Barlow, C., 2005. Glyoxalase 1 and glutathione reductase 1 regulate anxiety in mice. Nature 438, 662-666.

Huang, J., Perlis, R.H., Lee, P.H., Rush, A.J., Fava, M., Sachs, G.S., Lieberman, J., Hamilton, S.P., Sullivan, P., Sklar, P., Purcell, S., Smoller, J.W., 2010. Cross-disorder genomewide analysis of schizophrenia, bipolar disorder, and depression. Am J Psychiatry 167, 1254-1263.

Huang, P., Zhou, Y., Liu, Z., Zhang, P., 2016. Interaction between ANXA1 and GATA-3 in Immunosuppression of CD4(+) T Cells. Mediators Inflamm 2016, 1701059.

Huggins, A., Paschalidis, N., Flower, R.J., Perretti, M., D'Acquisto, F., 2009. Annexin-1-deficient dendritic cells acquire a mature phenotype during differentiation. FASEB J 23, 985-996.

Jones, K.H., Ford, D.V., Jones, P.A., John, A., Middleton, R.M., Lockhart-Jones, H., Osborne, L.A., Noble, J.G., 2012. A large-scale study of anxiety and depression in people with Multiple Sclerosis: a survey via the web portal of the UK MS Register. PLoS One 7, e41910.

Khandaker, G.M., Dantzer, R., Jones, P.B., 2017. Immunopsychiatry: important facts. Psychol Med 47, 2229-2237.

Kiecolt-Glaser, J.K., McGuire, L., Robles, T.F., Glaser, R., 2002. Emotions, morbidity, and mortality: new perspectives from psychoneuroimmunology. Annu Rev Psychol 53, 83-107. Kipnis, J., Cohen, H., Cardon, M., Ziv, Y., Schwartz, M., 2004. T cell deficiency leads to cognitive dysfunction: implications for therapeutic vaccination for schizophrenia and other psychiatric conditions. Proc Natl Acad Sci U S A 101, 8180-8185.

Lam, R.W., 2012. Onset, time course and trajectories of improvement with antidepressants. Eur Neuropsychopharmacol 22 Suppl 3, S492-498.

Laumet, G., Edralin, J.D., Chiang, A.C., Dantzer, R., Heijnen, C.J., Kavelaars, A., 2018. Resolution of inflammation-induced depression requires $\mathrm{T}$ lymphocytes and endogenous brain interleukin-10 signaling. Neuropsychopharmacology 43, 2597-2605. 
Lee, H.Y., Lee, M., Bae, Y.S., 2017. Formyl Peptide Receptors in Cellular Differentiation and Inflammatory Diseases. J Cell Biochem 118, 1300-1307.

Leoni, G., Nusrat, A., 2016. Annexin A1: shifting the balance towards resolution and repair. Biol Chem 397, 971-979.

Lorefice, L., Fenu, G., Trincas, G., Moro, M.F., Frau, J., Coghe, G.C., Cocco, E., Marrosu, M.G., Carta, M.G., 2015. Progressive multiple sclerosis and mood disorders. Neurol Sci 36, 1625-1631. Mao, S., Wu, F., Cao, X., He, M., Liu, N., Wu, H., Yang, Z., Ding, Q., Wang, X., 2016. TDRP deficiency contributes to low sperm motility and is a potential risk factor for male infertility. Am $\mathrm{J}$ Transl Res 8, 177-187.

Marin, I.A., Kipnis, J., 2017. Central Nervous System: (Immunological) Ivory Tower or Not? Neuropsychopharmacology 42, 28-35.

Matcham, F., Rayner, L., Steer, S., Hotopf, M., 2013. The prevalence of depression in rheumatoid arthritis: a systematic review and meta-analysis. Rheumatology (Oxford) 52, 2136-2148.

McIlwain, K.L., Merriweather, M.Y., Yuva-Paylor, L.A., Paylor, R., 2001. The use of behavioral test batteries: effects of training history. Physiol Behav 73, 705-717.

Migeotte, I., Communi, D., Parmentier, M., 2006. Formyl peptide receptors: a promiscuous subfamily of $\mathrm{G}$ protein-coupled receptors controlling immune responses. Cytokine Growth Factor Rev 17, 501-519.

Mihaylova, N., Bradyanova, S., Chipinski, P., Herbath, M., Chausheva, S., Kyurkchiev, D., Prechl, J., Tchorbanov, A.I., 2017. Annexin A1 as a target for managing murine pristane-induced systemic lupus erythematosus. Autoimmunity 50, 257-268.

Miller, A.H., Haroon, E., Felger, J.C., 2017. Therapeutic Implications of Brain-Immune Interactions: Treatment in Translation. Neuropsychopharmacology 42, 334-359.

Moraes, L.A., Ampomah, P.B., Lim, L.H.K., 2018. Annexin A1 in inflammation and breast cancer: a new axis in the tumor microenvironment. Cell Adh Migr, 1-7.

Moustafa, A.T., Moazzami, M., Engel, L., Bangert, E., Hassanein, M., Marzouk, S., Kravtsenyuk, M., Fung, W., Eder, L., Su, J., Wither, J.E., Touma, Z., 2020. Prevalence and metric of depression and anxiety in systemic lupus erythematosus: A systematic review and meta-analysis. Semin Arthritis Rheum 50, 84-94.

Muller, N., 2017. Immunological aspects of the treatment of depression and schizophrenia. Dialogues Clin Neurosci 19, 55-63.

Odobasic, D., Jia, Y., Kao, W., Fan, H., Wei, X., Gu, R., Ngo, D., Kitching, A.R., Holdsworth, S.R., Morand, E.F., Yang, Y.H., 2018. Formyl peptide receptor activation inhibits the expansion of effector T cells and synovial fibroblasts and attenuates joint injury in models of rheumatoid arthritis. Int Immunopharmacol 61, 140-149.

Paschalidis, N., Huggins, A., Rowbotham, N.J., Furmanski, A.L., Crompton, T., Flower, R.J., Perretti, M., D'Acquisto, F., 2010. Role of endogenous annexin-A1 in the regulation of thymocyte positive and negative selection. Cell Cycle 9, 784-793.

Paschalidis, N., Iqbal, A.J., Maione, F., Wood, E.G., Perretti, M., Flower, R.J., D'Acquisto, F., 2009. Modulation of experimental autoimmune encephalomyelitis by endogenous annexin A1. J

Neuroinflammation 6, 33.

Pederzoli-Ribeil, M., Maione, F., Cooper, D., Al-Kashi, A., Dalli, J., Perretti, M., D'Acquisto, F., 2010. Design and characterization of a cleavage-resistant Annexin A1 mutant to control inflammation in the microvasculature. Blood 116, 4288-4296.

Perretti, M., D'Acquisto, F., 2009. Annexin A1 and glucocorticoids as effectors of the resolution of inflammation. Nat Rev Immunol 9, 62-70. 
Pompili, M., Forte, A., Palermo, M., Stefani, H., Lamis, D.A., Serafini, G., Amore, M., Girardi, P., 2012. Suicide risk in multiple sclerosis: a systematic review of current literature. J Psychosom Res 73, 411-417.

Prata, J., Santos, S.G., Almeida, M.I., Coelho, R., Barbosa, M.A., 2017. Bridging Autism Spectrum Disorders and Schizophrenia through inflammation and biomarkers - pre-clinical and clinical investigations. J Neuroinflammation 14, 179.

Raper, D., Louveau, A., Kipnis, J., 2016. How Do Meningeal Lymphatic Vessels Drain the CNS? Trends Neurosci 39, 581-586.

Rattazzi, L., Piras, G., Ono, M., Deacon, R., Pariante, C.M., D'Acquisto, F., 2013. CD4(+) but not CD8(+) T cells revert the impaired emotional behavior of immunocompromised RAG-1-deficient mice. Transl Psychiatry 3, e280.

Reeves, W.H., Lee, P.Y., Weinstein, J.S., Satoh, M., Lu, L., 2009. Induction of autoimmunity by pristane and other naturally occurring hydrocarbons. Trends Immunol 30, 455-464.

Rossi, B., Constantin, G., 2016. Live Imaging of Immune Responses in Experimental Models of Multiple Sclerosis. Front Immunol 7, 506.

Scheinert, R.B., Haeri, M.H., Lehmann, M.L., Herkenham, M., 2016. Therapeutic effects of stress-programmed lymphocytes transferred to chronically stressed mice. Prog

Neuropsychopharmacol Biol Psychiatry 70, 1-7.

Sena, A.A., Glavan, T., Jiang, G., Sankaran-Walters, S., Grishina, I., Dandekar, S., Goulart, L.R., 2016. Divergent Annexin A1 expression in periphery and gut is associated with systemic immune activation and impaired gut immune response during SIV infection. Sci Rep 6, 31157.

Serretti, A., Chiesa, A., 2011. Sexual side effects of pharmacological treatment of psychiatric diseases. Clin Pharmacol Ther 89, 142-147.

Severance, E.G., Dickerson, F.B., Yolken, R.H., 2018. Autoimmune phenotypes in schizophrenia reveal novel treatment targets. Pharmacol Ther 189, 184-198.

Stempel, H., Jung, M., Perez-Gomez, A., Leinders-Zufall, T., Zufall, F., Bufe, B., 2016. Strain-

specific Loss of Formyl Peptide Receptor 3 in the Murine Vomeronasal and Immune Systems. J

Biol Chem 291, 9762-9775.

Taylor, G.T., Lerch, S., Chourbaji, S., 2017. Marble burying as compulsive behaviors in male and female mice. Acta Neurobiol Exp (Wars) 77, 254-260.

Tzelepis, F., Verway, M., Daoud, J., Gillard, J., Hassani-Ardakani, K., Dunn, J., Downey, J., Gentile, M.E., Jaworska, J., Sanchez, A.M., Nedelec, Y., Vali, H., Tabrizian, M., Kristof, A.S., King, I.L., Barreiro, L.B., Divangahi, M., 2015. Annexin1 regulates DC efferocytosis and crosspresentation during Mycobacterium tuberculosis infection. J Clin Invest 125, 752-768.

Uzun, S., Kozumplik, O., Jakovljevic, M., Sedic, B., 2010. Side effects of treatment with benzodiazepines. Psychiatr Danub 22, 90-93.

Wang, X., Jiang, H., Zhou, W., Zhang, Z., Yang, Z., Lu, Y., Lu, B., Wang, X., Ding, Q., Hu, R., 2010. Molecular cloning of a novel nuclear factor, TDRP1, in spermatogenic cells of testis and its relationship with spermatogenesis. Biochem Biophys Res Commun 394, 29-35.

Winther, M., Dahlgren, C., Forsman, H., 2018. Formyl Peptide Receptors in Mice and Men: Similarities and Differences in Recognition of Conventional Ligands and Modulating Lipopeptides. Basic Clin Pharmacol Toxicol 122, 191-198.

Wolf, S.A., Steiner, B., Akpinarli, A., Kammertoens, T., Nassenstein, C., Braun, A., Blankenstein, T., Kempermann, G., 2009. CD4-positive T lymphocytes provide a neuroimmunological link in the control of adult hippocampal neurogenesis. J Immunol 182, 3979-3984. 
Yang, Y.H., Song, W., Deane, J.A., Kao, W., Ooi, J.D., Ngo, D., Kitching, A.R., Morand, E.F., Hickey, M.J., 2013. Deficiency of annexin A1 in CD4+ T cells exacerbates T cell-dependent inflammation. J Immunol 190, 997-1007.

Yazid, S., Gardner, P.J., Carvalho, L., Chu, C.J., Flower, R.J., Solito, E., Lee, R.W., Ali, R.R., Dick, A.D., 2015. Annexin-A1 restricts Th17 cells and attenuates the severity of autoimmune disease. J Autoimmun 58, 1-11.

Zhumabekov, T., Corbella, P., Tolaini, M., Kioussis, D., 1995. Improved version of a human CD2 minigene based vector for T cell-specific expression in transgenic mice. J Immunol Methods 185, 133-140.

Zlokovic, B.V., Jovanovic, S., Miao, W., Samara, S., Verma, S., Farrell, C.L., 2000. Differential regulation of leptin transport by the choroid plexus and blood-brain barrier and high affinity transport systems for entry into hypothalamus and across the blood-cerebrospinal fluid barrier. Endocrinology 141, 1434-1441.

\section{Figures and Tables}

Figure 1. Autoimmune-prone phenotype of T-cell specific AnxA1 tg mice. (A) T cells from control and AnxA1 ${ }^{\text {tg }}$ mice were stimulated with the indicated concentration of plate-bound anti-CD3/CD28 for 16-18 hrs and then stained with anti-CD25 and anti-CD69 and analyzed by FACS. The numbers in the plot show the percentages of CD69 and CD25 double positive cells. Results are representative of $n=12-18$ experiments with similar results. (B) $\mathrm{T}$ cells from control and AnxA1 ${ }^{\text {tg }}$ mice were stimulated with the indicated concentration of plate-bound anti-CD3/CD28 for 24-30 $\mathrm{hr}$ and the supernatants used to measure the levels of IL-2. The bars show means \pm SEM $n=5$ separate mice and are representative of five experiments with similar results. Statistical significance between control and AnxA1 ${ }^{\text {tg }}$ cells was determined by two-way ANOVA followed by Bonferroni multiple-comparison test ** $\mathrm{p}<0.01 ; * * * \mathrm{p}<0.001 ; * * * * \mathrm{p}<0.0001$. (C) Control and AnxA1 ${ }^{\text {tg }}$ mice were immunized with $\mathrm{MOG}_{35-55}$ and CFA and monitored daily for clinical signs of EAE (top left panel) or weight gain/loss (top right panel) for 23 days. Results show means \pm SEM of $n=8$ mice per group and are representative of seven experiments with similar results. $* * * * \mathrm{p}<0.0001$ (two-way ANOVA followed by Bonferroni multiple-comparison test) indicates significant values compared to wild type control mice. The spinal cord sections showed in the bottom left panels were obtained at day 18 and stained with hematoxylin and eosin as described in Materials and Methods. The table in the bottom right corner shows the number of mice showing a score of 2 at different times during the development of the EAE. (D) Control and AnxA1 ${ }^{\text {tg }}$ mice received an intraperitoneal injection of pristane to induce a lupus-like disease and were monitored daily for survival (left panel) or weight gain/loss (right panel) for 35 days. Results show means \pm SEM of $n=10$ mice per group and are representative of three experiments with similar results. $* * * \mathrm{p}<0.001$ (two-way ANOVA followed by Bonferroni multiple-comparison test) indicates significant values compared to wild type control mice.

Figure 2. Phenotype of effector $T$ cells recovered from AnxA1 ${ }^{\text {tg }}$ mice subjected to MOG 35-55-induced EAE. Representative dot plots showing intracellular staining 
for IL-17 and IFN- $\gamma$ (top panels) or IL-17 and GM-CSF (bottom panels) of CD4 ${ }^{+} \mathrm{T}$ cells present in the draining lymph nodes (A) or spinal cords (B) of wild type and AnxA1 ${ }^{\text {tg }} \mathrm{T}$ cells sacrificed at the indicated time after $\mathrm{MOG}_{35-55}$ immunization. The bar graphs at the bottom show the total cell number of $\mathrm{CD}^{4} 5^{+}$mononuclear cells recovered after Ficoll (draining lymph nodes) or Percoll (spinal cord) purification as described in the Supplementary Materials and Methods. The bar graphs referring to $\mathrm{CD}^{+} \mathrm{T}$ cells show the number of these cells present in the same tissues. Values are expressed as means \pm SEM of $n=6$ mice for each group and are representative of three experiments with similar results. $* p<0.05 ; * * p<0.01$ (Student's $t$-test) indicate significant values compared to wild type control mice.

Figure 3. Increased signs of anxiety-like behavior in $T$ cell-specific $A n x A 1^{\text {tg }}$ mice. (A) $^{\text {(A) }}$ The bar graphs show the total duration (seconds) of digging, the latency (seconds) to the first digging bout and the total number of buried marbles during a 10-minute trial. (B) The bar graphs show the total time (seconds) spent in the lit area, latency (seconds) to first cross to the dark chamber and total number of crossings during a 5-minute trial. (C) The bar graphs show, the total time (seconds) spent on the climbing mesh, the latency (seconds) to the first climb and the number of climbing events during a 5-minute trial. (D) The bar graphs show total number of squares crossed, the number of rears and the latency (seconds) to the first rear during a 5minute session. Values are expressed as means \pm SEM of $n=12-20$ mice and are representative of four different experiments with similar results. $* \mathrm{p}<0.05$, $* * \mathrm{p}<0.01, * * * \mathrm{p}<0.001, * * * * \mathrm{p}<0.0001$ indicate significant values compared to wild type control mice (Mann-Whitney U-test).

Figure 4. Gene fingerprint of the whole brain of $T$ cell-specific AnxA1 ${ }^{\text {tg }}$ mice reveals several genes linked to anxiety-like behavior. (A) Summary of the gene expression profile of the whole brain of wild type and AnxA1 $1^{\text {tg }}$ mice showing the number of upregulated $(\mathrm{FC}>1)$ and downregulated $(\mathrm{FC}<1)$ differentially regulated genes (DEG). (B) Heatmap analysis on Microarray data of the whole brain of $n=3$ wild type and AnxA1 ${ }^{\text {tg }}$ mice. The heatmap analysis used annotated genes only (genes with EntrezID). (C) Real time PCR analysis of two genes of interest selected from the microarray. Values are presented as individual data points $\pm \mathrm{SEM}$ of $\mathrm{n}=8$ mice.

$* * * \mathrm{p}<0.001 ; * * * * \mathrm{p}<0.0001$ indicate significant values compared to wild type control mice (Student's $t$-test).

Figure 5. Imood expression in AnxA1 ${ }^{\text {tg }}$ mice. (A) Imood intracellular staining of CD4 ${ }^{+}$ $\mathrm{T}$ cells from $\mathrm{C} 57 \mathrm{BL} / 6$ mice cultured overnight in complete medium (Control) or stimulated with $1 \mu \mathrm{g} / \mathrm{ml}$ of plate-bound anti-CD3 or anti-CD3/CD28. The numbers in the gate represent the \% of Imood-high expressing cells. The histograms show the results obtained with a single mouse and are representative or $n=6-8$ animals with similar results. (B) Imood intracellular staining of $\mathrm{CD}^{+} \mathrm{T}$ from wild type or AnxA1 ${ }^{\text {tg }}$ mice cultured overnight in complete medium (Control) or stimulated with 
$1 \mu \mathrm{g} / \mathrm{ml}$ of anti-CD3/CD28. The numbers in the plots show the $\%$ of Imood-high expressing cells (in the brackets) and the median fluorescence intensity of the gated region. The histograms show the results obtained with a single mouse and are representative or $\mathrm{n}=6$ animals with similar results. (C) RT-PCR of Imood expression in $\mathrm{CD}^{+} \mathrm{T}$ cells from wild type and AnxA1 ${ }^{\text {tg }}$ mice cultured overnight in complete medium (Control) or stimulated with $1 \mu \mathrm{g} / \mathrm{ml}$ of plate-bound anti-CD3 or anti-CD3/CD28. Values are expressed as means \pm SEM of $n=6$ mice. ${ }^{* *} \mathrm{p}<0.01$; $* * * p<0.001$ indicate significant values compared to wild type control mice (Student's $t$-test). (D) The top panel shows the western blotting of the whole cell lysates of indicated number of freshly isolated $\mathrm{CD}^{+} \mathrm{T}$ cells from wild type and AnxA1 $1^{\text {tg }}$ mice. The bottom panel shows the levels of Imood immunoprecipitated from the cell culture medium of $\mathrm{CD}^{+}{ }^{+} \mathrm{T}$ cells from wild type and AnxA1 ${ }^{\text {tg }}$ mice cultured overnight in complete medium (Control) or stimulated with $1 \mu \mathrm{g} / \mathrm{ml}$ of plate-bound anti-CD3 or anti-CD3/CD28. Membranes were immunoblotted with a polyclonal anti-Imood antibody and recombinant Imood (r-Imood) was used as control. The results shown are from a single mouse and are representative of six mice with similar results.

Figure 6. Anxiolytic effects of anti-Immuno-moodulin antibodies. (A) AnxA1 $1^{\text {tg }}$ (grey bars) or C57BL/6 (white bars) mice received an intraperitoneal injection (100ng/ mouse) of anti-Imood antibodies 1B10 and 1C4 and then tested in the light and dark shuttle box test at day 7. The bar graphs show total number of crossings and the total time (seconds) spent in the lit area during a 5-minute trial. Values are expressed as means \pm SEM of $n=12$ mice $\left(A n x A 1^{\text {tg }}\right)$ or $n=15(C 57 B L / 6)$ mice and are representative of three experiments with similar results. $* * * * p<0.0001$ indicate significant values compared with PBS-injected control mice (Mann-Whitney Utest). (B) Real time PCR analysis of Imood in peripheral blood mononuclear cells of patients diagnosed with OCD as described in Materials and Methods. Values are presented as individual data points \pm SEM of 23 patients and 20 healthy control. Male and female subjects are coded as shown in the graph.

$* * * * \mathrm{p}<0.0001$ (Student's $t$-test) (C) Schematic summery of the study showing how physiological levels of both AnxA1 and Imood play a homeostatic role regulating host immune response and emotional wellbeing. $\mathrm{T}$ cell activation causes the release of AnxA1 and the externalization of its receptor FPR. This signaling pathway integrates with the TCR and contributes to the regulation of the strength of TCR signaling and the level of T cell activation. Activated T cells express higher levels of Imood. The release of this protein by T cells contribute to a physiological state of lower mood that is similar to the sickness behavior observed following an infection. The increased level of expression of AnxA1 in T cells observed in patients suffering from autoimmune diseases is responsible for the lower threshold of $T$ cell activation and the increased expression of Imood. The increased release of this protein in circulation leads to a state of higher anxiety and depression that is often observed in patients suffering from autoimmune conditions. 
Supplementary Table 1. Differential gene expression profile whole brain from $\mathbf{T}$ cell specific AnxA1 ${ }^{\text {tg }}$ mice. The table shows a list of genes differentially modulated in AnxA1 ${ }^{\text {tg }}$ brain compared to wild type controls. Probe ID is affymetrix ID.

Fold changes (FC) is logged value.

Supplementary Table 2. Differential gene expression profile of $\mathrm{CD4}^{+} \mathrm{T}$ cells from $\mathrm{T}$ cell specific AnxA1 ${ }^{\text {tg }}$ mice. The table shows a list of genes differentially modulated in AnxA1 $1^{\text {tg }} \mathrm{CD}^{+} \mathrm{T}$ cells compared to wild type controls. Probe ID is Affymetrix ID.

FC is logged value.

Supplementary Table 3. Social and clinical variables of OCD subjects.

Supplementary Table 4. List of antibodies used for FACS.

Supplementary Figure 1. Generation of AnxA1 ${ }^{\text {tg }}$ mice. (A) Agarose gel electrophoresis of the AnxA1-Flag tagged construct cloned in two different backbone vectors (pCR2.1 and pcDNA3.1) and digested by SmaI to confirm the cloning of $1047 \mathrm{bp}$ AnxA1 cDNA (indicated by the asterisk). (B) Schematic representation of the linearized construct that was used to generate T-cell specific AnxA1 ${ }^{\text {tg }}$ mice. The construct was inserted in the SmaI site of the VACD2 vector - just between the CD2 promoter sequence and CD2 locus control region (LCR) cassette. (C) The two agarose gels show the results of the PCR screening (for further details see Supplementary Material and Methods) of the 22 pups obtained from the pronuclear injection of VACD2-AnxA1-Flag construct. The top gels show the 3 mice that resulted positive for the transgene while the bottom show the PCR screening for the endogenous AnxA1 as control. (D) Western blotting of the whole cell lysate from purified equal number $\left(1 \times 10^{6}\right)$ of $\mathrm{T}$ cells of wild type and AnxA1 ${ }^{\text {tg }}$ mice showing increased expression of AnxA1 protein in transgenic mice.

Supplementary Figure 2. Immune repertoire of AnxA1 ${ }^{\text {tg }}$ mice. (A) Representative dot plots showing CD4/CD8 staining of thymus, spleen and lymph node T cells of wild type and AnxA1 ${ }^{\text {tg }} \mathrm{T}$ cells. (B) The bar graphs show the total cell number of cells purified from wild type and AnxA $1^{\text {tg }}$ mice as described in Supplementary Materials and Methods, section "Flow Cytometric analysis". Values are expressed as means \pm SEM of $n=6$ mice for each group and are representative of four experiments with similar results. $* * * * \mathrm{p}<0.01$ (Student's $t$-test) indicates significant values compared to wild type control mice. 
Supplementary Figure 3. Autoimmune-prone phenotype and heightened anxiety-like behavior AnxA1 ${ }^{\text {tg }}$ mice. (A) Control and AnxA1 ${ }^{\text {tg }}$ mice derived from the second founder (red line; see Results section for more details) were immunized with MOG $_{35-55}$ and CFA and monitored daily for clinical signs of EAE (top left panel) or weight gain/loss (top right panel) for 23 days. Results show means \pm SEM from $\mathrm{n}=10$ mice per group and are representative of three separate experiments with similar results. $* * * * \mathrm{p}<0.001$, (two-way ANOVA followed by Bonferroni multiplecomparison test) indicates significant values compared to wild type control mice. (B) The bar graphs on the left show the total duration (seconds) of digging and total number of buried marbles, during a 10-minute trial of the marble burying test. Those in the middle show the total time (seconds) spent in the lit area and total number of crossing during a 5-minute trial in the light/dark shuttle box test. The bar on the right show total number of squares crossed and the latency (seconds) to the first rearing during a 5-minute session in the open field test. Values are expressed as means \pm SEM of $n=15$ mice and are representative of three separate experiments with similar results. $* * * p<0.001 ; * * * * p<0.0001$ indicate significant values compared to wild type control mice (Mann-Whitney U-test).

Supplementary Figure 4. Increased signs of organ inflammation in AnxA1 ${ }^{\text {tg }}$ subjected to pristane-induced lupus. Control and AnxA1 ${ }^{\text {tg }}$ mice received an intraperitoneal injection of pristane to induce a lupus-like disease. After 4 weeks mice were culled and dissected to collect spleens and lungs. Tissues were fixed with 4\% PFA and then stained with hematoxylin and eosin. The panels in A show a photo picture of the spleen (left) and it relative histological section (right). The panels in B show a photo picture of the lung (left) and it relative histological sections (middle and right panels, 4x and 20x magnifications). Results are from a single mouse and are representative of $n=10$ mice with similar results.

Supplementary Figure 5. Effect of recombinant Imood on anxiety-like behavior of C57BL/6 mice. C57BL/6 mice were injected with PBS or r-Imood or denaturated r-Imood (d-Imood) (500ng, i.p.; https://www.origene.com; Recombinant protein of human chromosome 8 open reading frame 42 (C8orf42), catalogue number TP313199) and tested at day 7 post injection. The bar graphs show the total time (seconds) spent in the lit area and total number of crossings during a 5-minute trial. Values are expressed as means \pm SEM of $n=12$ mice and are representative of three experiments with similar results. $* * * * \mathrm{p}<0.01$ indicates significant values compared to PBS-injected control mice. $\S \S \mathrm{p}<0.01 ; \S \S \S \mathrm{p}<0.001$ indicate significant values compared to d-Imood-injected mice. (Mann-Whitney U-test).

Supplementary Figure 6. Effect of anti-Imood polyclonal antibody on anxiety-like behavior of C57BL/6 and AnxA1 tg mice. C57BL/6 and AnxA1 ${ }^{\text {tg }}$ mice received an i.p. injection of polyclonal anti-Imood or IgG control antibodies (500ng i.p.) and then tested at day 7. The bar graphs show the total time (seconds) spent in the lit area and total number of crossings during a 5-minute trial. Values are expressed as means \pm SEM of $n=12$ mice and are representative of three experiments with 
similar results. $* * * \mathrm{p}<0.001 ; * * * * \mathrm{p}<0.0001$, indicate significant values compared to IgG-injected control mice (Mann-Whitney U-test).

\section{Supplementary Figure 7. Screening and identification of $1 \mathrm{~B} 10$ and $1 \mathrm{C} 4$ monoclonal} anti-Imood antibodies. (A) Aliquots (50ng) of recombinant Imood were loaded on an SDS-page gel and then transferred on PVDF membranes as detailed in Materials and Methods. Membranes were immunoblotted with the supernatants from different hybridoma cultures (code names indicated on the top of the top panel). Thereafter, the same membranes were stripped and immunoblotted with a commercially available anti-Imood antibody (bottom panel). (B) Aliquots (50ng) of recombinant Imood were immunoprecipitated with hybridoma supernatants and then loaded on an SDS-page gel as detailed in Materials and Methods. Membranes were immunoblotted with a commercially available anti-Imood antibody. 